\title{
Observed Sensitivity of Low-Cloud Radiative Effects to Meteorological Perturbations over the Global Oceans
}

\author{
RyAn C. SCOtt, ${ }^{\mathrm{a}, \mathrm{e}}$ Timothy A. Myers, ${ }^{\mathrm{b}}$ JOEl R. NORRis, ${ }^{\mathrm{a}}$ MARK D. ZElinkA, ${ }^{\mathrm{b}}$ STEPHEN A. KLein, ${ }^{\mathrm{b}}$ \\ Moguo Sun, ${ }^{\mathrm{c}}$ AND DAVID R. DOELlinG ${ }^{\mathrm{d}}$ \\ ${ }^{a}$ Scripps Institution of Oceanography, La Jolla, California \\ ${ }^{b}$ Lawrence Livermore National Laboratory, Livermore, California \\ ${ }^{c}$ Science Systems and Applications, Inc., Hampton, Virginia \\ ${ }^{d}$ NASA Langley Research Center, Hampton, Virginia
}

(Manuscript received 31 December 2019, in final form 27 April 2020)

\begin{abstract}
Understanding how marine low clouds and their radiative effects respond to changing meteorological conditions is crucial to constrain low-cloud feedbacks to greenhouse warming and internal climate variability. In this study, we use observations to quantify the low-cloud radiative response to meteorological perturbations over the global oceans to shed light on physical processes governing low-cloud and planetary radiation budget variability in different climate regimes. We assess the independent effect of perturbations in sea surface temperature, estimated inversion strength, horizontal surface temperature advection, 700-hPa relative humidity, 700-hPa vertical velocity, and near-surface wind speed. Stronger inversions and stronger cold advection greatly enhance low-level cloudiness and planetary albedo in eastern ocean stratocumulus and midlatitude regimes. Warming of the sea surface drives pronounced reductions of eastern ocean stratocumulus cloud amount and optical depth, and hence reflectivity, but has a weaker and more variable impact on low clouds in the tropics and middle latitudes. By reducing entrainment drying, higher free-tropospheric relative humidity enhances low-level cloudiness. At low latitudes, where cold advection destabilizes the boundary layer, stronger winds enhance low-level cloudiness; by contrast, wind speed variations have weak influence at midlatitudes where warm advection frequently stabilizes the marine boundary layer, thus inhibiting vertical mixing. These observational constraints provide a framework for understanding and evaluating marine low-cloud feedbacks and their simulation by models.
\end{abstract}

\section{Introduction}

Marine low-level clouds play a fundamental role in Earth's climate by modulating radiant energy exchange between Earth and outer space. They efficiently reflect incoming solar radiation back to space while only weakly reducing the emission of terrestrial radiation to space, thereby exerting a strong cooling effect on the planet. Changes in their global coverage and reflectivity have long been understood to have the potential to amplify

Supplemental information related to this paper is available at the Journals Online website: https://doi.org/10.1175/JCLI-D-19-1028.s1.

\footnotetext{
${ }^{\mathrm{e}}$ Current affiliation: Science Systems and Applications, Inc., Hampton, Virginia.
}

Corresponding author: Ryan C. Scott, ryan.c.scott@nasa.gov or mitigate global warming via radiative feedbacks (Schneider 1972; Slingo 1990; Norris et al. 2016; Zhu et al. 2019). For example, a decrease in their global coverage or reflectivity as the climate warms would amplify the positive radiative forcing from increasing greenhouse gas concentrations in the atmosphere, constituting a positive feedback that amplifies the global temperature response, and vice versa. However, uncertainty in the key physical processes governing their present-day variability and their response to climate perturbations has plagued climate sensitivity estimates for decades. Most global climate models fail to simulate low-cloud processes realistically and hence diverge widely in their simulated feedback to global warming $(\mathrm{Qu}$ et al. 2014; Sherwood et al. 2014; Myers and Norris 2015; Zelinka et al. 2016, 2020). In addition, low clouds play a key role in regional air-sea feedbacks that control the emergence, amplification, and persistence of coherent patterns of low-frequency sea surface temperature (SST) 
variability (Bellomo et al. 2016; Brown et al. 2016; Yuan et al. 2016, 2018) and climate extremes like the recent marine "heatwave" off Baja California (Myers et al. 2018a). Given their importance, these clouds have been intensively studied for decades using data from ships, weather stations, aircraft, islands, and satellites. However, global-scale observational constraints on the physical processes governing marine low-cloud variability and feedbacks have remained elusive.

Covering more of Earth's surface than any other cloud type, stratocumulus clouds play an especially critical role in Earth's top-of-atmosphere (TOA) and surface radiation budget (Wood 2012). Stratocumulus clouds preferentially form in shallow, well-mixed, surfacecoupled boundary layers capped by a sharp temperature inversion under a dry and subsiding free troposphere. Accordingly, they are prevalent over eastern subtropical ocean basins and in the cold postfrontal sector of midlatitude cyclones (Norris and Iacobellis 2005; Naud et al. 2016). Previous studies, primarily focusing on subtropical stratocumulus, show that stratocumulus cloud cover increases in response to colder SST (Norris and Leovy 1994), stronger temperature inversions capping the marine boundary layer (MBL; Klein and Hartmann 1993; Wood and Bretherton 2006), stronger low-level airflow from cold to warm SST (Klein et al. 1995; Myers and Norris 2015; Seethala et al. 2015), and weaker large-scale subsidence (Myers and Norris 2013). The physical mechanisms underlying these relationships involve close interactions among radiation, turbulence, and microphysics. Longwave (LW) cloud-top radiative cooling drives a convective vertical mixing process in the boundary layer that supplies clouds with moisture from the underlying sea surface. Cloud formation and dissipation is controlled by differences between the supply of moisture from the surface and the mixing of relatively dry air from aloft into the MBL. Stronger temperature inversions require more turbulent kinetic energy to mix free-tropospheric air across the inversion and tend to trap moisture at low levels, thereby favoring more low-level cloud. Warmer SST increases the temperature and saturation vapor pressure in the MBL and weakens the capping inversion if the free-tropospheric temperature remains constant. In turn, stronger in-cloud latent heating enhances turbulence and entrainment of drier air from aloft into the MBL, thereby favoring less low-level cloud. Low-level airflow from cold to warm SST introduces relatively cool and dry air over warmer water, which destabilizes the MBL and enhances sea-to-air sensible and latent heat fluxes, thereby favoring more low-level cloud. Weaker subsidence pushes down on the MBL less strongly, allowing clouds to grow higher and thicken, thereby favoring more low-level cloud.
A number of recent studies have used observations to decompose the low-cloud sensitivity to meteorology as a basis for predicting their feedback to global warming $(\mathrm{Qu}$ et al. 2015; Zhai et al. 2015; Brient and Schneider 2016; Myers and Norris 2016; McCoy et al. 2017; Klein et al. 2017). These studies infer reductions in low-level cloud cover and shortwave (SW) cooling over stratocumulusdominated eastern oceans, driven by large increases in SST relative to its natural range of variability; similar behavior emerges in large-eddy simulations (LES; Bretherton et al. 2013; Bretherton and Blossey 2014; Bretherton 2015; Tan et al. 2017; Schneider et al. 2019). However, previous analyses examined relatively small areas of the planet, which may not be globally representative. Furthermore, these studies did not quantify the total radiative impact of all changes in low-level cloud properties. Similar decompositions have been successfully used to study multidecadal climate variability (Seethala et al. 2015), the low-cloud response to midlatitude jet shifts (Zelinka et al. 2018), and aerosol-cloud interactions (Adebiyi and Zuidema 2018). Nonetheless, they too focused on limited areas of the planet. Globally, low-level clouds form and evolve in vastly different meteorological environments (Figs. 1 and 2) that produce clouds having different morphologies, dynamics, and radiative effects. Downwind of core stratocumulus regions, weaker subsidence and advection over warmer tropical SSTs favor deepening and decoupling of the MBL (Bretherton and Wyant 1997). Such structural changes in the MBL cause stratocumulus decks to break up and transition to shallow trade-wind cumulus clouds (Klein et al. 1995; Norris 1998; Wood and Bretherton 2004). Stratiform cloud systems, including marine stratus and stratocumulus, also cover large swaths of the midlatitude oceans in both hemispheres, especially in summer when they reflect substantial solar radiation back to space. While low-latitude marine low clouds have been intensively studied, there have been relatively few satellite-based studies of the climatological variations of trade cumulus and their covariance with the large-scale meteorology (Brueck et al. 2015; Mieslinger et al. 2019). Low clouds over the midlatitude ocean basins have not been studied as intensively as their low-latitude counterparts, although there have been a growing number of studies devoted to understanding dynamical controls on midlatitude low-cloud formation and reflectivity (e.g., Grise and Medeiros 2016; Kelleher and Grise 2019) and investigations of low-cloud variability across SST fronts (Liu et al. 2016; Naud et al. 2016; Miyamoto et al. 2018). Nonetheless, many questions remain about how low clouds respond to large-scale environmental perturbations in different climate regimes and how the dominant mechanisms vary from one regime to the next. 
a) Upper-Level Cloud Fraction

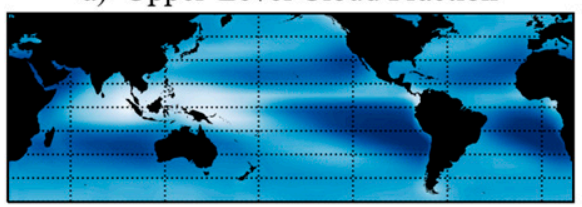

c) Non-obscured Low Cloud Fraction

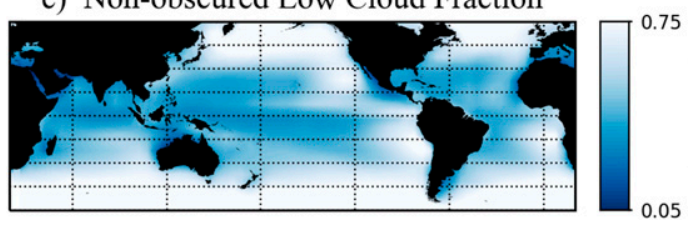

b) Satellite-Reported Low Cloud Fraction
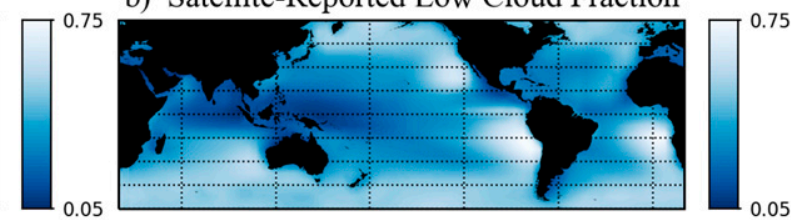

d) Low Cloud Radiative Effect $\left[\mathrm{W} \mathrm{m}^{-2}\right]$

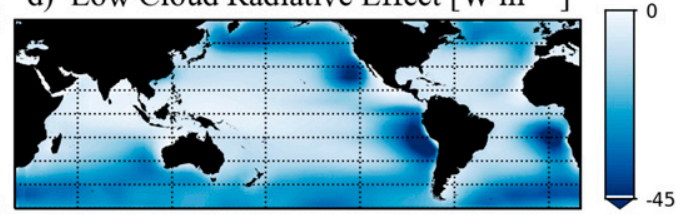

FIG. 1. Annual mean climatology (2002-18) of the CERES-FBCT: (a) upper-level cloud fraction, (b) satellitereported low-level cloud fraction, (c) nonobscured low-level cloud fraction, and (d) total (SW + LW) low-level cloud radiative effect (CRE), defined as the difference in outgoing TOA radiative flux between clear-sky and allsky conditions, accounting for low-level clouds only. Larger negative low-level CRE values indicate stronger lowcloud radiative cooling effects.

In this study, we combine satellite cloud and radiation measurements with coincident meteorological fields to evaluate the sensitivity of marine low-cloud radiative effects to perturbations in the large-scale meteorological environment across eastern-ocean stratocumulus, trade cumulus, tropical ascent, and midlatitude regimes. We seek insight into the mechanisms governing low clouds globally across different cloud types and meteorological environments to provide a physical basis for constraining low-cloud feedbacks to greenhouse warming and internal climate variability, and evaluating their simulation by models. Using multiple linear regression analysis, we quantify the independent but geographically specific effect of perturbations in SST, estimated inversion strength (EIS; Wood and Bretherton 2006), horizontal surface temperature advection (Tadv), 700-hPa relative humidity $\left(\mathrm{RH}_{700}\right), 700$-hPa pressure vertical velocity $\left(\omega_{700}\right)$, and near-surface wind speed (WS). These parameters, hereafter referred to collectively as $x_{i}$, serve as proxies for the vertical turbulent fluxes of heat, moisture, and momentum among the sea surface, MBL, and free troposphere. SST, Tadv, and WS influence upward fluxes from the a) $\mathrm{SST}[\mathrm{K}]$

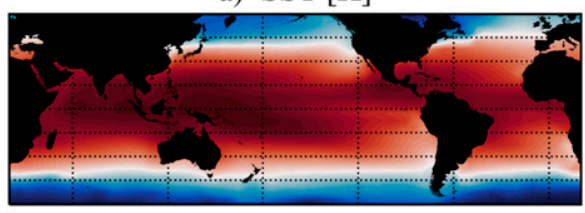

c) $\operatorname{Tadv}[\mathrm{K} / \mathrm{day}]$

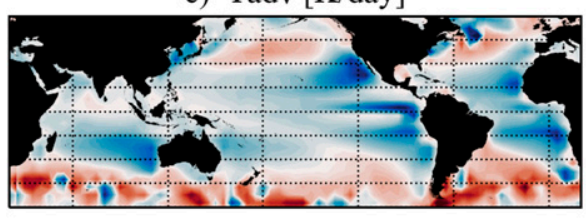

e) $\omega_{700}[\mathrm{hPa} /$ day $]$

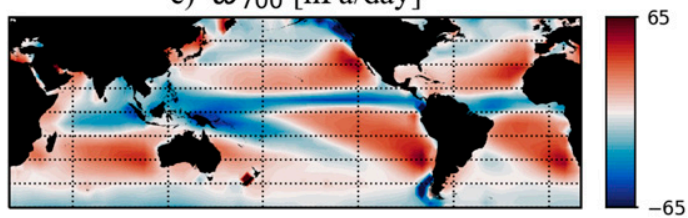

b) EIS $[\mathrm{K}]$

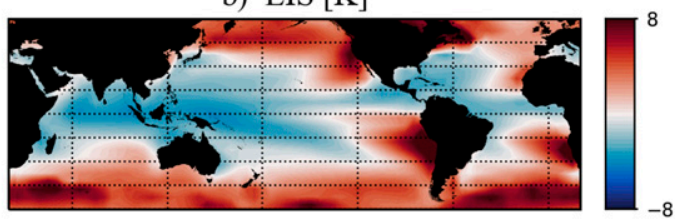

d) $\mathrm{RH}_{700}[\%]$
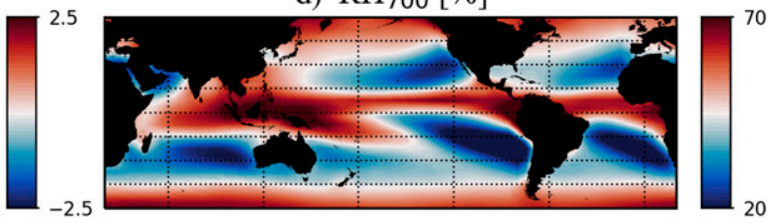

f) WS $[\mathrm{m} / \mathrm{s}]$

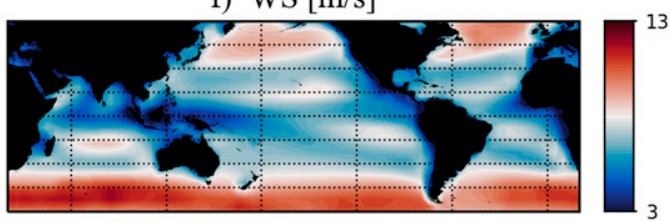

FIG. 2. Annual mean climatology (2002-18) of the large-scale meteorological cloud-controlling factors: (a) sea surface temperature (SST), (b) estimated inversion strength (EIS), (c) horizontal surface temperature advection (Tadv), (d) 700-hPa relative humidity $\left(\mathrm{RH}_{700}\right)$, (e) 700-hPa pressure vertical velocity $\left(\omega_{700}\right)$, and (f) near-surface wind speed (WS). 
surface into the MBL, while EIS, $\mathrm{RH}_{700}$ and $\omega_{700}$ influence downward fluxes from aloft into the MBL. Because changes in free-tropospheric cloudiness can affect the amount of low cloud retrieved by spaceborne passive imagers, we develop two novel methods to account for upper-level cloud variability and obscuration effects, enabling us to perform "cloud-controlling factor analysis" (Klein et al. 2017) at a near-global scale. The regression coefficients quantify the sensitivity of the low-cloudinduced radiative flux to observed interannual variations in each meteorological parameter, with all other local meteorological conditions held constant. The coefficients can be multiplied by a meteorological change $\left(\Delta x_{i}\right.$; e.g., associated with climate warming) or anomaly ( $x_{i}^{\prime} ;$ e.g., associated with a climate mode of variability) to obtain its independent contribution to the total low-cloud radiative change or anomaly, and may therefore be considered as meteorological cloud radiative kernels. In addition to understanding how clouds respond to their environment, the results provide a framework for (i) estimating marine low-cloud feedbacks to climate warming, including the role of different SST "pattern effects" (Stevens et al. 2016) or changes in large-scale atmospheric dynamics (Zelinka et al. 2018), (ii) examining low-cloud feedbacks to internal climate variability (Zhang et al. 2014; Myers et al. 2018b; Middlemas et al. 2019), (iii) interpreting observed multidecadal climate trends (Seethala et al. 2015), and (iv) improving the performance of LES and global climate models, among other applications.

In the following we provide a detailed description of the cloud, radiation, and meteorological data used. We then outline our methodology for deriving the sensitivity of marine low-cloud and associated TOA radiation fields to observed interannual fluctuations in the largescale environment and for partitioning the ocean into meteorological regimes. We then interpret the regression slopes in terms of the physical processes and mechanisms contributing to the observed low-cloud and radiative variability. Finally, we summarize the results and discuss implications for low-cloud feedbacks.

\section{Observational data}

\section{a. Satellite cloud and radiation observations}

The primary source of cloud and radiation data used in this study is the National Aeronautics and Space Administration (NASA) Clouds and the Earth's Radiant Energy System (CERES) Flux by Cloud Type (FBCT) dataset (Eitzen et al. 2017). CERES-FBCT provides monthly mean cloud fraction $f$ and cloud-induced TOA radiative fluxes $R$ stratified into seven cloud-top pressure and six cloud optical depth categories, as well as clear-sky radiative fluxes. The all-sky radiative fluxes are based on the CERES instrument calibration. Cloud properties are retrieved from narrowband radiances observed by the Moderate-Resolution Imaging Spectroradiometer (MODIS) instruments aboard the Terra and Aqua spacecraft using the algorithms described by Minnis et al. (2011). In this study, we use a beta version of the FBCT product; notably, we obtain similar results with the CERES partial radiative perturbation dataset (Thorsen et al. 2018).

We also use histograms of monthly mean cloud fraction stratified by cloud-top pressure and cloud optical depth from Collection 6.1 of the MODIS cloud products (Platnick et al. 2015), the International Satellite Cloud Climatology Project (ISCCP; Rossow and Schiffer 1999) D1 dataset, and the Advanced Very High Resolution Radiometer (AVHRR) Pathfinder Atmospheres Extended (PATMOS-x; Heidinger et al. 2014) dataset. To optimize sampling of the diurnal cycle, we average the data from Terra and Aqua MODIS. For each dataset, we derive cloud-induced TOA radiative fluxes using the cloud radiative kernels of Zelinka et al. (2012a), modified for use with observations by Zhou et al. (2013), using the methodology outlined below. These cloud-radiative kernels quantify the TOA radiative sensitivity to perturbations in the histogram-partitioned cloud fraction. They were calculated using the $\mathrm{Fu}$-Liou radiative transfer model using 2000-10 zonal mean vertical profiles of temperature, water vapor, and ozone from the European Centre for Medium-Range Weather Forecasts (ECMWF) interim reanalysis (ERA-Interim; Dee et al. 2011).

In all datasets we consider low-level clouds as those having a cloud-top pressure exceeding $680 \mathrm{hPa}$ (the first two cloud-top pressure bins denoted by $p=1,2$ ), and those having a cloud-top pressure less than $680 \mathrm{hPa}$ as upper-level or free-tropospheric clouds. To ensure that the MBL has adequate time to adjust to the ambient meteorological environment (Klein et al. 1995; Mauger and Norris 2010), all datasets were averaged to a $5^{\circ} \times 5^{\circ}$ grid using cosine of latitude area weighting.

\section{b. Large-scale meteorological fields}

We use monthly fields of SST from the National Oceanic and Atmospheric Administration (NOAA) Optimum Interpolation (OI) SST product, version 2 (Reynolds et al. 2002), which provides spatially complete maps of SST based on merged satellite, ship, and buoy observations. All other meteorological fields come from the ERA5 global reanalysis. The estimated inversion strength (EIS), a metric of the temperature inversion capping the MBL, is estimated following Wood and Bretherton (2006) as 


$$
\mathrm{EIS}=\mathrm{LTS}-\Gamma_{m}^{850}\left(Z_{700}-Z_{\mathrm{LCL}}\right),
$$

where LTS stands for lower-tropospheric stability, defined as the difference in potential temperature between $700 \mathrm{hPa}$ and the surface, $\Gamma_{m}^{850}$ is the moist-adiabatic lapse rate at $850 \mathrm{hPa}, Z_{700}$ is the height of the $700-\mathrm{hPa}$ pressure level relative to the surface, and $Z_{\mathrm{LCL}}$ is the height of the lifting condensation level relative to the surface. The calculation of EIS requires fields of 700-hPa temperature, $Z_{700}$, and surface temperature and pressure. We calculate the surface dewpoint temperature assuming a surface relative humidity of $80 \%$, as in previous studies. To calculate $Z_{\mathrm{LCL}}$, we use the method of Georgakakos and Bras (1984). Low-level advection over the SST gradient, hereafter referred to as horizontal surface temperature advection, is computed as

$$
\mathrm{Tadv}=-\frac{U_{10}}{R_{E} \cos \phi} \frac{\partial \mathrm{SST}}{\partial \lambda}-\frac{V_{10}}{R_{E}} \frac{\partial \mathrm{SST}}{\partial \phi}
$$

using a second-order centered finite-difference scheme, where $U_{10}$ and $V_{10}$ represent the zonal and meridional wind components $10 \mathrm{~m}$ above the sea surface, $\phi$ is latitude, $\lambda$ is longitude, and $R_{E}$ is the mean Earth radius. Additional fields include monthly mean $\mathrm{RH}_{700}$, $\omega_{700}$, and scalar WS (computed as the average WS over each analysis time period). We repeated our analysis using NASA's Modern-Era Retrospective Analysis for Research and Applications, version 2 (MERRA-2; Gelaro et al. 2017) and ERA-Interim. Our conclusions are insensitive to the choice of reanalysis and our use of NOAA SST data instead of reanalysis surface temperature.

\section{Methodology}

\section{a. Accounting for free-tropospheric cloud variability}

In addition to influencing low-level clouds, perturbations in surface forcing or meteorological conditions aloft also exert important controls on free-tropospheric clouds (Yuan and Oreopoulos 2013; Li et al. 2015). Globally, more free-tropospheric cloud is favored by negative $\omega_{700}$ anomalies and positive $\mathrm{RH}_{700}$ anomalies. In the deep tropics, positive SST anomalies tend to intensify deep convection, favoring a greater presence of cirriform anvil cloud. Under such conditions, a spaceborne passive imager will retrieve less low-level cloud simply because more upper-level cloud is present. To avoid such contamination of the inferred low-cloud sensitivity to meteorology, it is imperative to distinguish the actual meteorologically forced low-cloud change from satellite-reported changes that merely result from obscuration by free-tropospheric clouds.
In this study, we develop two novel methods to account for these effects. This enables us to examine how lowlevel clouds covary with meteorology on a global basis. Our first approach is to adjust for the amount of upperlevel cloud present in each grid box. By normalizing the satellite-retrieved low-cloud fraction $L=\sum_{p=1}^{2} \sum_{\tau=1}^{6} f_{p \tau}$ by the upper-level clear-sky fraction, we define the nonobscured or nonoverlapped low-cloud fraction as

$$
L_{n}=\frac{L}{1-U},
$$

where $U=\sum_{p=3}^{7} \sum_{\tau=1}^{6} f_{p \tau}$ is the upper-level cloud fraction; $L_{n}$ represents the total low-level cloud fraction relative to the area of each grid box not covered by upper-level cloud.

The upper-level cloud fraction maximizes over the tropical convergence zones and midlatitude storm tracks (Fig. 1a) where ascent frequently cools and humidifies the free troposphere (Figs. 2d,e). Upper-level cloud minima occur over subtropical eastern oceans where descent warms and dries the free troposphere, promoting a lowlevel inversion (Fig. 2b) that favors highly reflective stratocumulus clouds (Figs. 1b,d). The nonobscured low-cloud fraction maximizes over eastern subtropical oceans, and the midlatitude oceans where extensive low-level cloud systems experience moderate rates of overlap by clouds in the free troposphere (Yuan and Oreopoulos 2013).

By expanding each term in Eq. (3) as the climatological monthly mean plus an anomaly, averaging over each term, and subtracting the result from the initial expansion, one finds that perturbations in the low-level, nonobscured low-level, and upper-level cloud fraction are related by

$$
L^{\prime}=L_{n}^{\prime}(1-\bar{U})-U^{\prime} \overline{L_{n}}-\left(U^{\prime} L_{n}^{\prime}-\overline{U^{\prime} L_{n}^{\prime}}\right) .
$$

Anomalies in the satellite-reported low-cloud fraction $L^{\prime}$ may result from changes in the nonobscured lowcloud fraction, changes in the nonobscured area caused by changes in the upper-level cloud fraction, and covarying changes in the low- and upper-level cloud fraction. Differentiating Eq. (4) with respect to $x_{i}$, while neglecting small second-order and covariance terms, provides a linear expression relating the low- and upperlevel cloud fraction sensitivities to meteorology, each of which may be estimated through multilinear regression (Figs. S1-S4 in the online supplemental material).

\section{b. Computation of anomalous low-cloud-induced radiative fluxes}

As mentioned above, CERES-FBCT provides monthly mean cloud fraction $f$ and CERES-derived radiative fluxes $R$ in seven cloud-top pressure and six optical depth 
categories $(p, \tau)$, as well as clear-sky radiative fluxes $R_{\mathrm{clr}}$. Our methodology for calculating low-cloud-induced radiative flux anomalies with these data is outlined as follows. We first decompose the all-sky flux at TOA, given by

$$
R_{\mathrm{all}}=\sum_{p=1}^{7} \sum_{\tau=1}^{6} f_{p \tau} R_{p \tau}+R_{\mathrm{clr}}\left(1-\sum_{p=1}^{7} \sum_{\tau=1}^{6} f_{p \tau}\right),
$$

by expanding each term into the climatological monthly mean plus a perturbation. Averaging over each term in the resulting expansion provides an expression for the monthly mean flux. Subtracting the result from the original expansion provides an expression relating the TOA radiative flux anomaly to perturbations in cloud and background clear-sky radiative properties. We neglect noncloud radiative perturbations $R_{\mathrm{clr}}^{\prime}$, a small term involving $R_{p \tau}^{\prime}$, and small second-order and covariance terms. By isolating terms only involving perturbations in low-level cloud fraction, the monthly low-cloud radiative anomaly is given by

$$
R_{L}^{\prime}=\sum_{p=1}^{2} \sum_{\tau=1}^{6}\left(\overline{R_{p \tau}}-\overline{R_{c l}}\right) f_{p \tau}^{\prime} .
$$

The term in parentheses is equivalent to the climatological (negative) cloud radiative effect in each $p-\tau$ category, and is thus analogous to the cloud radiative kernels of Zelinka et al. (2012a). The primary difference is that this term is based on the observed radiation climatology as determined by the local atmospheric structure at each grid box. Following Zelinka et al. (2012b), we account for perturbations in the distribution of low-cloud fraction among cloud-top pressure and optical depth categories by subtracting the proportionate change in low-cloud fraction from the cloud fraction anomaly in each $p-\tau$ bin

$$
f_{p \tau}^{\prime \prime}=f_{p \tau}^{\prime}-\overline{f_{p \tau}} \frac{L^{\prime}}{\bar{L}},
$$

where $L^{\prime}=\sum_{p=1}^{2} \sum_{\tau=1}^{6} f_{p \tau}^{\prime}$ and $\bar{L}=\sum_{p=1}^{2} \sum_{\tau=1}^{6} \overline{f_{p \tau}}$. The term $f_{p \tau}^{\prime \prime}$ is the anomaly resulting from a shift of cloud fraction from one $p-\tau$ bin to another and corresponds to a change in overall low-cloud optical depth and/or cloud-top pressure with no change in overall low-cloud fraction. With this definition, Eq. (6) becomes

$R_{L}^{\prime}=\left[\sum_{p=1}^{2} \sum_{\tau=1}^{6}\left(\overline{\frac{R_{p \tau}}{f_{p \tau}}}\right)-\overline{R_{\mathrm{clr}}}\right] L^{\prime}+\sum_{p=1}^{2} \sum_{\tau=1}^{6}\left(\overline{R_{p \tau}}-\overline{R_{\mathrm{clr}}}\right) f_{p \tau}^{\prime \prime}$.

The first term on the right side of Eq. (8) depicts the radiative impact of satellite-reported low-cloud fraction anomalies $L^{\prime}$ with no change in overall low-cloud optical depth and cloud-top pressure. The second term represents radiative perturbations associated with changes in low-cloud optical depth and/or cloud-top pressure as represented by a shift of cloud fraction from one $p-\tau$ bin to another with no change in overall low-cloud fraction. To obtain radiative flux anomalies induced by nonobscured low clouds, we modify Eq. (8) by noting that the sum over $f_{p \tau}^{\prime}$, if performed over all cloud-top pressure and optical depth categories, represents $L^{\prime}+U^{\prime}$. Adding $U^{\prime}$ to both sides of Eq. (4), the total cloud fraction perturbation may be expressed, to leading order, as

$$
L^{\prime}+U^{\prime}=L_{n}^{\prime}(1-\bar{U})+U^{\prime}\left(1-\overline{L_{n}}\right) .
$$

This equation states that the total cloud fraction perturbation is the sum of the perturbation in lowlevel cloud fraction, weighted by the area fraction not covered by upper-level clouds, plus the perturbation in upper-level cloud fraction, weighted by the area fraction not covered by low-level clouds. By retaining the portion of the sum only involving low-level clouds, we transform variables by replacing $L^{\prime}$ in Eq. (8) with $L_{n}^{\prime}(1-\bar{U})$. This method ignores any upper-level cloud perturbation that occurs over low-level clouds and any low-level cloud perturbation that occurs merely due to obscuring effects of upper-level clouds. These are second-order effects [Eq. (4)], and neither affects the total cloud perturbation.

For MODIS, ISCCP, and PATMOS-x, we obtain lowcloud-induced TOA radiative flux anomalies by applying the cloud radiative kernels of Zhou et al. (2013) to nonobscured low-cloud fraction and satellite-reported low-cloud fraction anomalies in each $p-\tau$ bin. We then sum over all low-level cloud categories to obtain the anomalous radiative fluxes.

\section{c. Marine cloud regimes from large-scale meteorology}

Figure 2 presents the annual mean cloud-controlling meteorological fields of SST, EIS, Tadv, $\mathrm{RH}_{700}, \omega_{700}$, and WS. While below we present the regionally resolved low-cloud radiative response to meteorology for each $5^{\circ} \times 5^{\circ}$ grid box, it is also useful to summarize the results by climate regimes containing different cloud types. To that end, in a manner similar to Medeiros and Stevens (2011), we partition the ocean from $60^{\circ} \mathrm{S}$ to $60^{\circ} \mathrm{N}$ into eastern ocean stratocumulus, trade cumulus, tropical ascent, and midlatitude regimes using annual mean climatological thresholds of $\omega_{700}$ and EIS. Figure 3 identifies which grid boxes belong to each regime and highlights contrasts in meteorology among each of the regimes. We define the stratocumulus regime as grid 


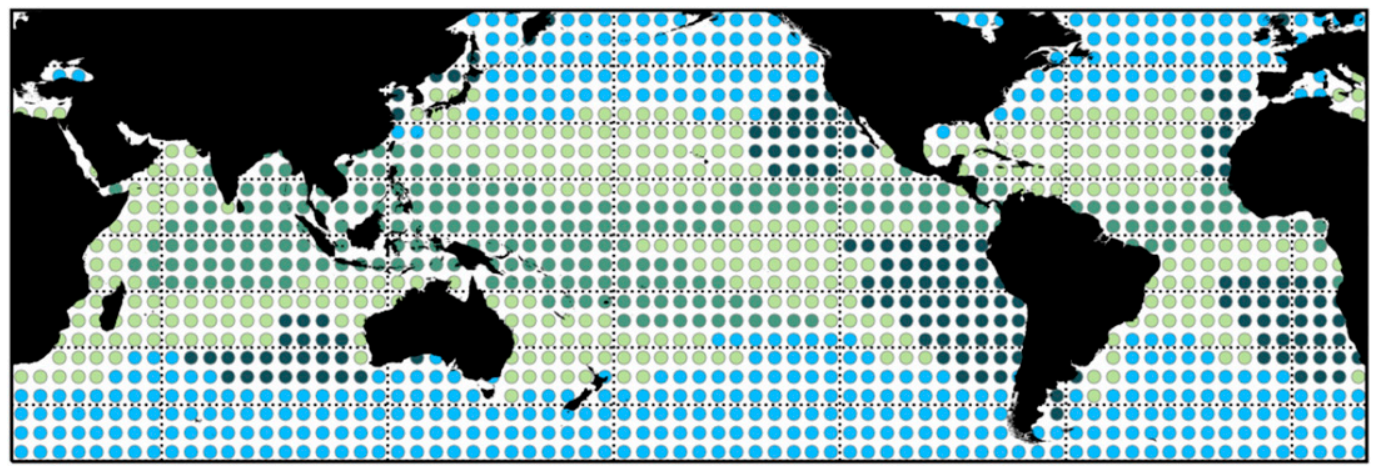

a) SST

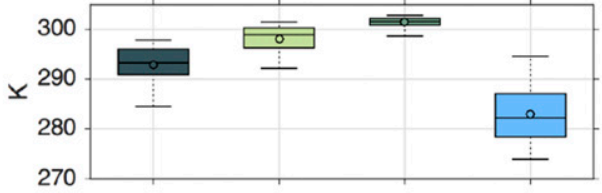

c) Tadv

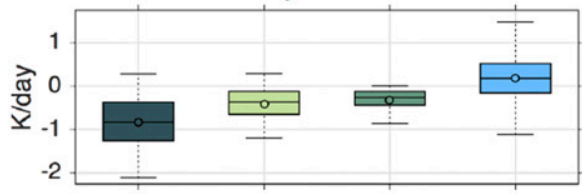

e) $\omega_{700}$

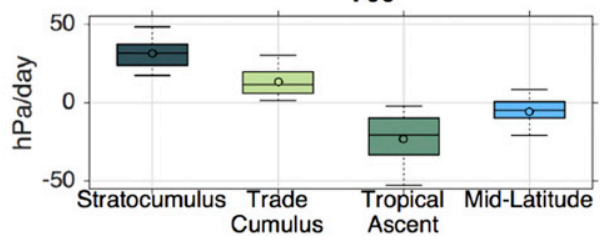

b) EIS

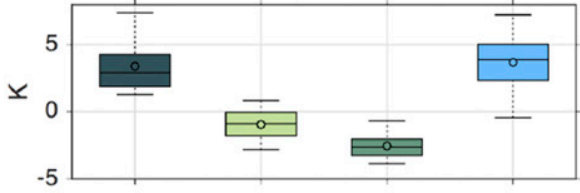

d) $\mathrm{RH}_{700}$

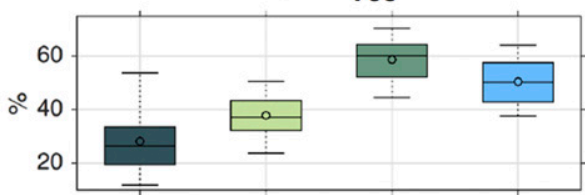

f) WS

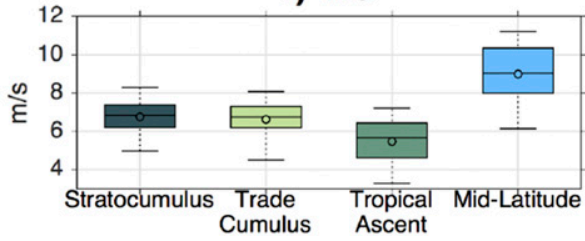

FIG. 3. (top) Stratocumulus (8.5\%), trade cumulus (20.5\%), tropical ascent (15\%), and midlatitude (21.8\%) cloud regimes partitioned using annual mean climatological thresholds of $\omega_{700}$ and EIS (percentages indicate the area of the planet covered by each regime). (a)-(f)Box-and-whisker plots highlight differences in the background meteorological environment in each regime. The mean is indicated by circles, the interior line indicates the median, boxes extend to the 25 th and 75 th percentiles, and whiskers extend to the 5th and 95th percentiles.

boxes with strong subsidence $\left(\omega_{700}>15 \mathrm{hPa} \mathrm{day}^{-1}\right)$ and a strong inversion (EIS $>1 \mathrm{~K}$ ). It is largely confined to the descending branches of the Hadley and Walker circulations, and is dominated by relatively cool tropical SST, cold Tadv, low $\mathrm{RH}_{700}$, weak WS, large low-level cloud fraction, and small upper-level cloud fraction. The trade cumulus regime encompasses grid boxes experiencing subsidence $\left(\omega_{700}>\right.$ $0 \mathrm{hPa} \mathrm{day}{ }^{-1}$ ) and a weak inversion (EIS $<1 \mathrm{~K}$ ). It is characterized by relatively warm SST, weak cold Tadv, moderately low $\mathrm{RH}_{700}$, weak WS, and a small low-level cloud fraction. The tropical ascent regime includes grid boxes equatorward of $25^{\circ} \mathrm{S}$ and $25^{\circ} \mathrm{N}$ with $\omega_{700}<0 \mathrm{hPa} \mathrm{day}^{-1}$. Here low clouds, typically of the shallow cumulus variety, experience uniformly warm SST, weak cold Tadv, weak WS, and high $\mathrm{RH}_{700}$ linked to frequent deep convection. The midlatitude regime accounts for all remaining grid boxes including those poleward of $25^{\circ} \mathrm{S}$ and $25^{\circ} \mathrm{N}$ with $\omega_{700}<$ $15 \mathrm{hPa} \mathrm{day}^{-1}$ and EIS $>1 \mathrm{~K}$, or $\omega_{700}<0 \mathrm{hPa} \mathrm{day}^{-1}$. It is characterized by cold SST, variable but predominantly warm Tadv, large EIS, high $\mathrm{RH}_{700}$, high WS, large low-level cloud fraction, and moderate upperlevel cloud fraction.

\section{d. Low-cloud radiative sensitivity to meteorology}

We develop two models to quantify the low-cloud radiative sensitivity to perturbations in the large-scale 
meteorological environment. Both assume that lowcloud radiative properties may be expressed as a linear function of the local meteorological environment. For the first model, hereafter referred to as model 1 , at each ocean grid box between $60^{\circ} \mathrm{S}$ and $60^{\circ} \mathrm{N}$, we regress deseasonalized and detrended interannual monthly anomalies of the nonobscured low-cloudinduced radiative flux $R_{L_{n}}^{\prime}$ onto deseasonalized, detrended, and standardized interannual monthly anomalies of the large-scale meteorology $x_{i}^{\prime}$. Standardizing the meteorological anomalies places them on the same scale and allows us to compare the cloud radiative response to a typical size anomaly in each predictor. In this case, the low-cloud radiative perturbation is modeled as

$$
R_{L_{n}}^{\prime}=\sum_{i=1}^{6}\left(\frac{\partial R_{L_{n}}}{\partial x_{i}}\right) x_{i}^{\prime}+\varepsilon,
$$

where $\varepsilon$ is an error term (Fig. S5). The regression coefficients $\beta_{i}$ depict the sensitivity of the low-cloudinduced radiative flux to a local standard deviation $(1 \sigma)$ anomaly in $x_{i}$, with all other meteorological conditions held fixed; they therefore represent partial derivatives $\partial R_{L_{n}} / \partial x_{i}$, as written above.

For the second model, hereafter referred to as model 2, at each ocean grid box between $60^{\circ} \mathrm{S}$ and $60^{\circ} \mathrm{N}$, we regress deseasonalized and detrended interannual monthly anomalies of the satellite-retrieved low-cloud-induced radiative flux $R_{L}^{\prime}$ onto deseasonalized, detrended, and standardized interannual monthly anomalies of the large-scale meteorology $x_{i}^{\prime}$, but we also include the upper-level cloud fraction anomaly $U^{\prime}$ as an additional predictor in the multilinear regression model. Because $L^{\prime}$ is to first-order linearly related to $U^{\prime}$ by Eq. (4), upper-level cloud obscuration effects are represented by $\partial R_{L} / \partial U$ (or $\partial L / \partial U$ in the case of cloud fraction), allowing the remaining coefficients $\partial R_{L} / \partial x_{i}$ to approximate the true low-cloud radiative response to meteorology. In this case, the low-cloud radiative perturbation is modeled as

$$
R_{L}^{\prime}=\sum_{i=1}^{6}\left(\frac{\partial R_{L}}{\partial x_{i}}\right) x_{i}^{\prime}+\left(\frac{\partial R_{L}}{\partial U}\right) U^{\prime}+\varepsilon .
$$

By enhancing the downward flux of LW radiation incident upon low clouds, free-tropospheric clouds can reduce low-level cloudiness by reducing cloud-top radiative cooling and the associated overturning circulations that mix moisture upward from the underlying sea surface (Christensen et al. 2013). However, these effects can only be observed in passive satellite imagery if free-tropospheric cloud rapidly dissipates or strong vertical wind shear causes low clouds to become uncovered by free-tropospheric clouds.

\section{e. Regression coefficient uncertainty}

We evaluate the statistical significance of the regression coefficients by forming a $95 \%$ confidence interval at each grid box using the methodology outlined in the appendix. Covariability among the predictors tends to inflate the uncertainty of the regression coefficients. To detect multicollinearity among the predictors, we calculated variance inflation factors (VIFs; Fig. S6). At most grid boxes, the VIFs are less than 5 for each predictor. Along a thin band of the equatorial Pacific, from the coast of South America to the date line, the SST and EIS values exceed 5, indicating that the coefficients may be unreliable in this isolated region. We also computed maps of correlations among each of the meteorological predictors to identify locations where the meteorology may covary strongly enough to affect the regression results (not shown) and we also assessed how the coefficients change between single-factor and multifactor regression models.

To accurately isolate the effect of each meteorological parameter, any regression model must include all legitimate cloud-controlling factors to avoid confounding influence from other relevant factors. For example, while a model using only SST as a predictor exhibits a similar spatial structure of coefficients as that employing a more comprehensive set of parameters (Fig. S7 and section 4b below), failure to account for all legitimate cloud-controlling factors that covary with SST will exert confounding influence on the SST coefficients. As additional predictors are included in the model, the coefficients will change by an amount given by

$$
\frac{\partial R}{\partial \mathrm{SST}}=\frac{d R}{d \mathrm{SST}}-\left(\sum_{j} \frac{\partial R}{\partial x_{j}} \frac{d x_{j}}{d \mathrm{SST}}\right) .
$$

Thus, the degree to which the coefficients change in a given grid box is determined by local magnitude and sign of $\partial R / \partial x_{j}$ and the correlation between $x_{j}$ and SST. By including EIS, $\partial R / \partial S S T$ decreases everywhere relative to the 1 -factor model since $\partial R / \partial \mathrm{EIS}<0$ and EIS and SST are negatively correlated $(d \mathrm{EIS} / d \mathrm{SST}<0)$. By also including Tadv, $\partial R / \partial \mathrm{SST}$ decreases at most locations since $\partial R / \partial \mathrm{Tadv}<0$, and $d \mathrm{Tadv} / d \mathrm{SST}$ is weakly positive at most grid boxes except the equatorial Pacific and Atlantic, where it is negative. Large changes in coefficients are only observed in the equatorial Pacific adjacent to South America where SST and EIS strongly covary $(r \sim-0.95)$ and VIFs exceed 5 (Fig. S6). 
a) Total $R^{2}$ Model 1

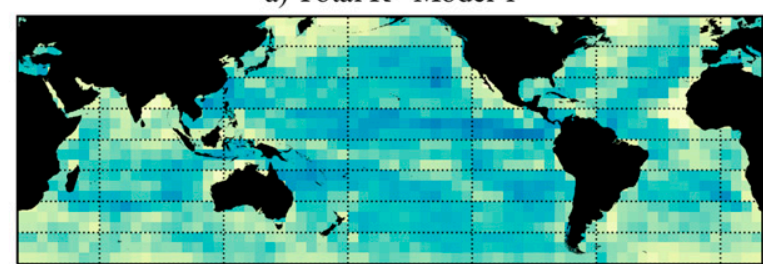

b) Total $\mathrm{R}^{2}$ Model 2

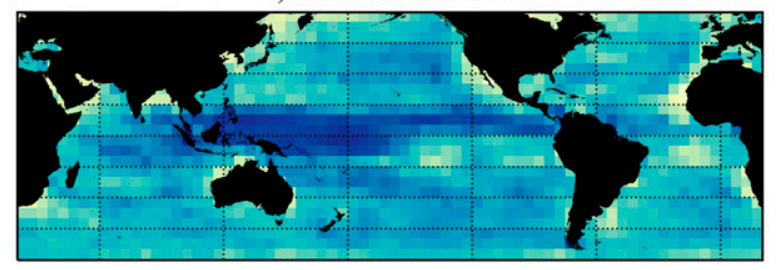

$0.0 \quad 0.2$

0.4

0.6

0.8

1.0

FIG. 4. Total variance $R^{2}$ in low-cloud-induced radiative fluxes explained by (a) model 1: $R_{L_{n}}^{\prime}$ regressed on $x_{i}^{\prime}$; and (b) model 2: $R_{L}^{\prime}$ regressed on $x_{i}^{\prime}$ and $U^{\prime}$.

\section{Results}

\section{a. Variance in low-cloud radiative properties explained}

Figure 4 presents the total variance in low-cloudinduced radiative fluxes explained by each multilinear regression model. The domain-wide mean variance $\left(60^{\circ} \mathrm{S}-60^{\circ} \mathrm{N}\right)$ explained by model 1 is $37 \%\left(R_{L_{n}}\right.$ regressed on $x_{i}$ ) while that explained by model 2 is $51 \%$ $\left(R_{L}\right.$ regressed on $x_{i}$ and $U$ ). Although model 2 explains higher variance, both models show similar spatial patterns of total $R^{2}$ and the higher variance explained by model 2 is attributed to the $U$ predictor. The regression coefficients and the variance uniquely explained by each meteorological parameter are nonetheless similar for both models. EIS and Tadv account for the bulk of the unique variance in low-cloud radiative properties in the stratocumulus and midlatitude regimes (Fig. S8), consistent with Zelinka et al. (2018). $\mathrm{RH}_{700}$ and WS contribute more unique variance in the tropics. Globally, SST and $\omega_{700}$ account for minimal unique variance in low-cloud-radiative properties. WS accounts for considerable variance in low-cloud amount in the trade cumulus regime (not shown), consistent with previous investigations of shallow cumulus dynamics (e.g., Mieslinger et al. 2019; Nuijens and Siebesma 2019).

Time series of low-cloud radiative fluxes reconstructed using Eqs. (10) and (11) are strongly and positively correlated with the original time series of low-cloud radiative fluxes for both models; Pearson correlation coefficients $r$ exceed 0.5 at virtually every grid box (not shown). Since the coefficients are so similar for both models, in the remainder of the paper we present results for the first model; for completeness, results for the second model are included in the supplemental material.

\section{b. Low-cloud radiative response to observed interannual climate variability: Physical mechanisms and regime dependence}

How do the mechanisms driving low-cloud and radiative variability compare across regimes and what might explain this behavior? Figures 5-7 show maps of linear regression coefficients quantifying the nonobscured low-cloud radiative sensitivity to perturbations in each meteorological parameter $x_{i}$, with all other local meteorological conditions held constant (the magnitude of a typical size anomaly in each $x_{i}$ is shown in Fig. S9). In particular, Fig. 5 shows the impact of all changes in lowcloud properties, whereas Fig. 6 shows the effect of changes in nonobscured low-cloud fraction, and Fig. 7 shows the effect of changes in low-cloud altitude and optical depth. Regime-averaged coefficients are shown in Fig. 8. Positive values indicate a net gain of energy by the climate system through a reduction in low-level cloudiness and total low-cloud radiative effect, whereas negative values indicate a net loss of energy. Similar coefficients for the low-level cloud amount, cloud optical depth, cloud altitude, and individual fluxes in the SW and LW bands are included in the supplemental materials (Figs. S1 and S10-S13). Since sea surface warming is the largest change in cloud-controlling factors simulated by climate models under global warming and many modes of coupled climate variability have prominent spatial signatures in SST, we begin by examining the low-cloud response to perturbations in SST.

Warmer SST increases the temperature and saturation vapor pressure in the MBL and enhances the vertical humidity gradient between the MBL and the free troposphere. With more energy and moisture in the MBL, more latent heat is released during cloud formation, resulting in greater in-cloud buoyancy and stronger production of turbulent kinetic energy in the MBL. This in turn promotes increased entrainment of free-tropospheric air into the MBL. Subsequent mixing desiccates the MBL and promotes dissipation of low-cloud. Reductions in low-level cloud cover in a warmer climate have been widely attributed to such a process (e.g., Rieck et al. 2012; Sherwood et al. 2014; Bretherton 2015; Vial et al. 2016).

Figures 5a, 6a, and 7a show that perturbations in SST exert a spatially variable impact on low clouds and their radiative properties across the global ocean. Over eastern ocean stratocumulus regions, warming of the sea surface drives strong reductions of low-level cloud amount and optical thickness (Figs. S1a and S10a). These reductions contribute roughly equally to strong 
a) $\partial \mathrm{R} / \partial \mathrm{SST}$

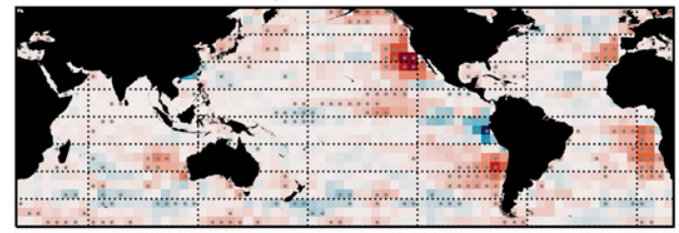

c) $\partial \mathrm{R} / \partial \mathrm{Tadv}$

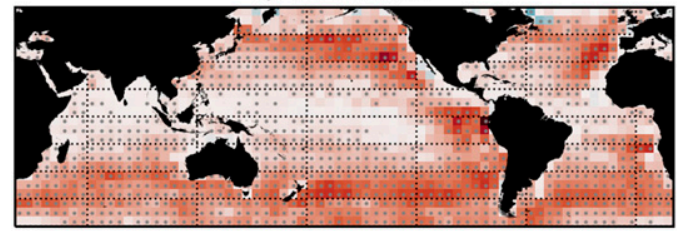

e) $\partial \mathrm{R} / \partial \omega_{700}$

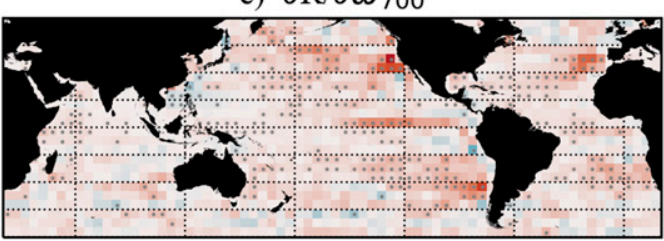

b) $\partial \mathrm{R} / \partial \mathrm{EIS}$

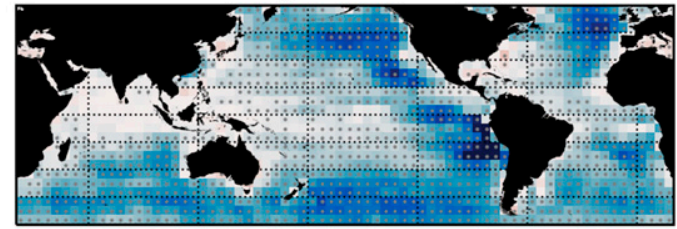

d) $\partial \mathrm{R} / \partial \mathrm{RH}_{700}$

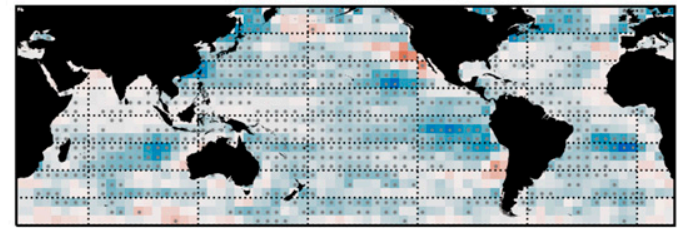

f) $\partial \mathrm{R} / \partial \mathrm{WS}$

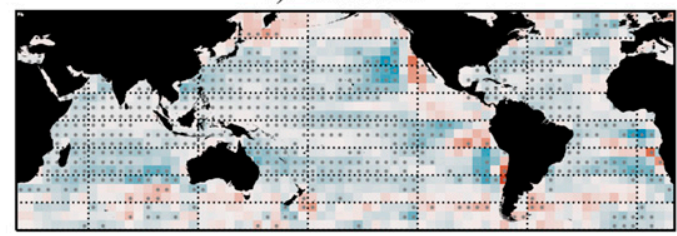

4

$\mathrm{W} \mathrm{m} \mathrm{m}^{-2} \sigma^{-1}$

FIG. 5. Linear regression coefficients quantifying the sensitivity of the nonobscured low-cloud-induced radiative flux $R_{L_{n}}$ to a local standard deviation ( $1 \sigma$ ) anomaly in (a) SST, (b) EIS, (c) Tadv, (d) $\mathrm{RH}_{700}$, (e) $\omega_{700}$, and (f) WS. Each coefficient represents the observed impact of a change in $x_{i}$ on low-cloud-induced energy flows at the top of the atmosphere, with all other local meteorological parameters $x_{j \neq i}$ held constant. Thus, changes in EIS due to changes in SST and changes in EIS due to changes in $\omega_{700}$ are not included in the coefficients. Positive values indicate a net gain of energy by the local climate system, and vice versa. Stippling indicates where the coefficients are statistically significant at the $95 \%$ confidence level.

radiant energy gain by the local climate system (Figs. 5a, 6a, 7a, and 8); regression slopes reach as large as $5 \mathrm{~W} \mathrm{~m}^{-2} \sigma^{-1}$ off the California coast (Fig. 5a). Tradewind cumulus clouds exhibit a similar albeit weaker sensitivity to perturbations in underlying SST, as recently found by Cesana et al. (2019). As the MBL is advected over warmer tropical SSTs, subcloud turbulent circulations may fail to penetrate to the surface as a stable subcloud layer forms near cloud base, reducing coupling to the surface moisture supply (Bretherton and Wyant 1997; Wyant et al. 1997; Xiao et al. 2011; Wood 2012). Another possible explanation for this behavior is the "cumulus valve mechanism" (Neggers et al. 2006; Nuijens et al. 2014; Vial et al. 2017). As surface moisture fluxes increase, the convective mass flux out of the MBL increases, ventilating the MBL and producing deeper cumulus clouds that, in turn, enhance mixing of free-tropospheric air downward into the subcloud layer. This raises the lifting condensation level, acting as a negative feedback that suppresses convection.
Slight reductions in trade cumulus radiative flux with surface warming are consistent with Rieck et al. (2012), who found that MBL drying dominates over increased cloud water content (albedo).

Relatively weak and spatially variable SST sensitivity is also observed over the colder midlatitude oceans. Kawai et al. (2017) showed that low-level stratiform cloud cover is more sensitive to SST fluctuations in warm SST and low $\mathrm{RH}_{700}$ environments. Such conditions are associated with a sharp vertical moisture gradient, strong in-cloud latent heating, and high rates of cloud-top entrainment drying. While eastern ocean stratocumulus clouds experience relatively warm SST and a dry free troposphere, conducive to strong turbulent mixing of dry air into the MBL, midlatitude marine low clouds experience colder SST and a relatively humid free troposphere, conducive to weak mixing of moist air into the MBL (Figs. 3a,d). Changes in the vertical moisture gradient are also smaller at colder temperatures, which may additionally 


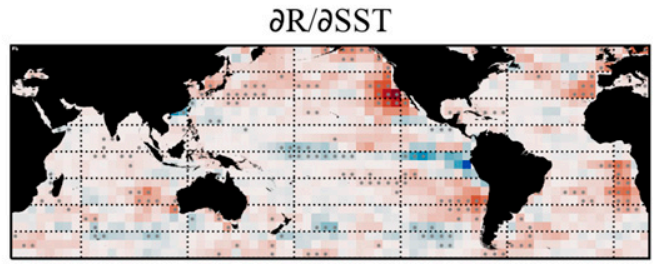

$\partial \mathrm{R} / \partial \mathrm{Tadv}$
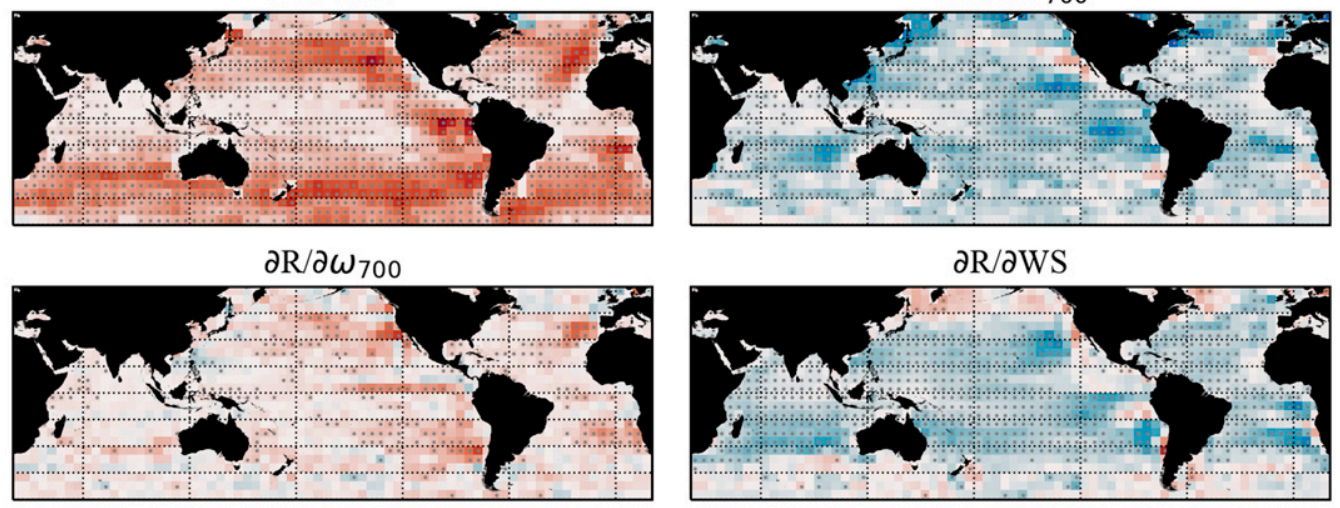

$-3.0$

$-1.5$

0.0

$\mathrm{W} \mathrm{m}^{-2} \sigma^{-1}$

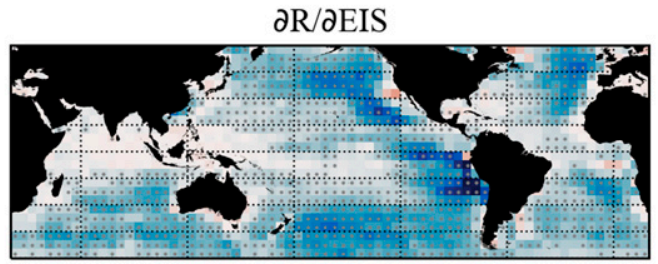

$\partial \mathrm{R} / \partial \mathrm{RH}_{700}$

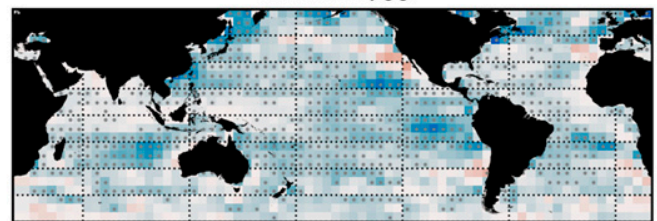

$\partial \mathrm{R} / \partial \mathrm{WS}$

1.5

FIG. 6. As in Fig. 5, but for the first term in Eq. (8) depicting the radiative sensitivity to perturbations in nonobscured low-cloud fraction.

contribute to weaker entrainment drying at midlatitudes (Kawai et al. 2017).

Changes in EIS exert a strong, first-order influence on low clouds and their radiative effects across much of the global ocean (Figs. 5b, 6b, and 7b). By inhibiting entrainment of relatively dry air from aloft and promoting a shallower MBL (Fig. S11b), stronger temperature inversions trap moisture at low levels, favoring a greater horizontal coverage and opacity of low-level clouds (Figs. S1b and S10b; Klein and Hartmann 1993; Wood and Bretherton 2006). Stability-driven increases in low-level cloud amount and optical depth induce roughly equal increases in outgoing radiative flux at TOA (Fig. 8). The response is strongest in the eastern ocean stratocumulus and midlatitude regimes where strong capping inversions prevail. By contrast, it is comparatively weak in the tropics where capping inversions tend to be weak or absent.

Changes in Tadv similarly exert a strong, first-order influence on low clouds and their radiative effects across much of the global ocean (Figs. 5c, 6c, and 7c). Low-level advection from cold to warm SST brings relatively cool and dry air over warmer water, which triggers enhanced upward turbulent fluxes of heat and moisture from the sea surface, providing a strong source of moisture for cloud formation. Conversely, low-level airflow from warm to cold SST brings relatively warm and moist air over cooler water, which stabilizes the MBL and cuts off clouds from the surface moisture supply. Midlatitude ship-based observations reveal how episodes of warm Tadv promote cloud-surface decoupling (Zheng and Li 2019). At virtually every grid box, stronger cold Tadv is associated with increases in low-level cloud amount and optical depth (Figs. S1c and S10c), and hence radiative effect. Enhancement of surface heat and moisture fluxes also promotes a deeper MBL (Fig. S11c). The strongest response is observed in the stratocumulus regime and along the $30^{\circ}-50^{\circ}$ latitude zone in each hemisphere. Variations in Tadv have a weaker impact on tropical cumulus fields where Tadv is weak and Tadv variability is low (Fig. S9c). If the near-surface air is close to saturation, sufficiently strong warm Tadv may lead to the formation of fog. While this phenomenon is not well captured by the multilinear regression model, such conditions are typically not reached except for in isolated geographic regions (Klein and Hartmann 1993).

Variations in $\mathrm{RH}_{700}$ can influence low clouds via two competing mechanisms. Higher free-tropospheric relative humidity results in less evaporation of cloud droplets per unit mass of air entrained into the MBL, 


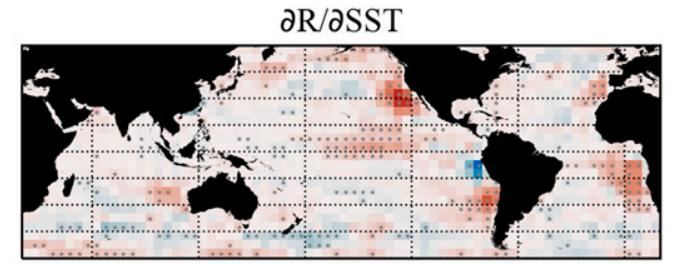

$\partial \mathrm{R} / \partial \mathrm{Tadv}$
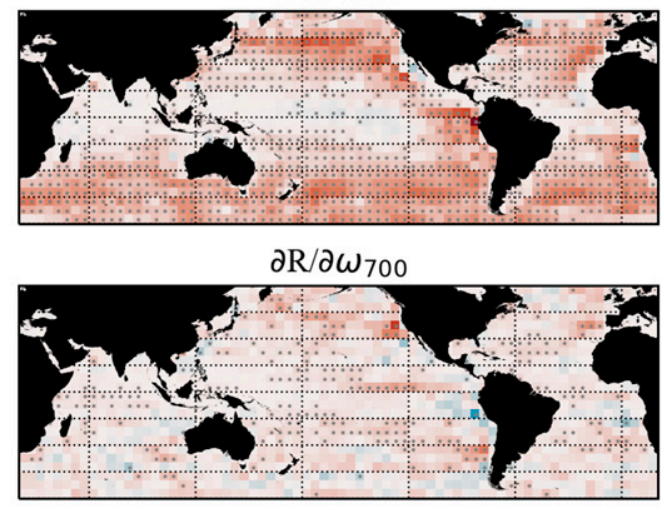

$-1.5$

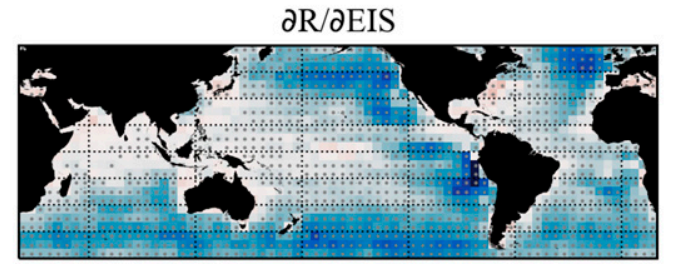

$\partial \mathrm{R} / \partial \mathrm{RH}_{700}$

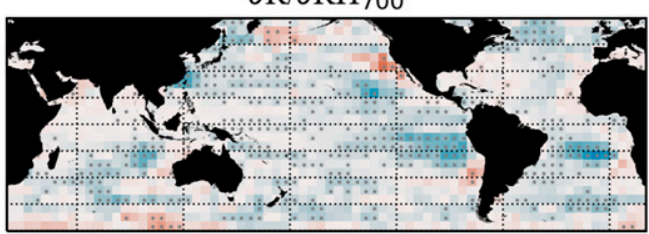

$\partial \mathrm{R} / \partial \mathrm{WS}$

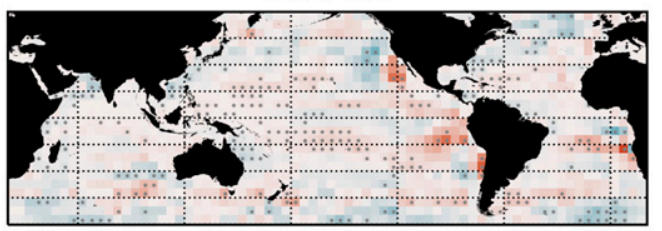

$-3.0$

0.0

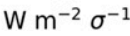

FIG. 7. As in Fig. 5, but for the second term in Eq. (8) depicting the radiative sensitivity to concurrent changes in low-cloud optical depth and cloud-top pressure.

thereby favoring more low-level cloud. At the same time, more free-tropospheric moisture emits more downwelling LW radiation, which can weaken cloudtop radiative-cooling and the overturning circulations that mix moisture up from the surface, thereby favoring less low-level cloud (Christensen et al. 2013). At most grid boxes, the former effect dominates; that is, higher $\mathrm{RH}_{700}$ favors more and optically thicker low-level cloud, consistent with LES results (van der Dussen et al. 2015) and previous observational studies (Myers and Norris 2015; Eastman and Wood 2018). This enhances low-cloud radiative cooling effects at TOA (Figs. $5 \mathrm{~d}, 6 \mathrm{~d}, 7 \mathrm{~d}$, and 8 ). The response is largest over tropical oceans where there are large horizontal $\mathrm{RH}_{700}$ gradients (Figs. 2d and 5d). Changes in $\mathrm{RH}_{700}$ have a weaker and more variable impact at midlatitudes where the free troposphere is relatively moist. While some grid boxes show an opposite signal, the response is rarely distinct from zero.

Enhanced free-tropospheric subsidence reduces the depth of the MBL, favoring decreases in cloud-top height, cloud amount, and cloud optical thickness (Figs. S11e, S1e, and S10e; Myers and Norris 2013). This effect is especially apparent over low-latitude subsidence zones containing stratocumulus and shallow cumulus clouds. However, the radiative impact of these changes is relatively small owing to competing responses in the SW and LW bands (Figs. S12e and S13e). Lower cloud tops emit at warmer temperatures, which decreases their LW radiative warming effect and allows Earth to radiate to space with greater efficiency. At the same time, reductions in low-level cloud amount and opacity allow more SW energy to be absorbed by the climate system. Overall, the latter effect dominates, favoring a net gain of energy by the climate system.

Stronger winds increase evaporation from the sea surface and promote deepening of the MBL (Fig. S11f; Kazil et al. 2016; Mieslinger et al. 2019). They also create surface gravity waves that can break and produce whitecaps and sea spray, further enhancing the sea-to-air latent heat flux. Over tropical oceans, where warm SSTs favor large surface moisture fluxes and cold Tadv destabilizes the MBL, stronger winds promote increases in low-level cloud amount (Fig. 6f and Fig. S1f). However, increases in cloud fraction are partially offset by reductions in cloud optical thickness and/or increases in cloud-top height, especially in the stratocumulus regime (Figs. $7 \mathrm{f}$ and 8 ). In simulations of marine stratocumulus, Kazil et al. (2016) found that wind-driven moistening of the MBL enhances the production of turbulent kinetic energy via stronger 


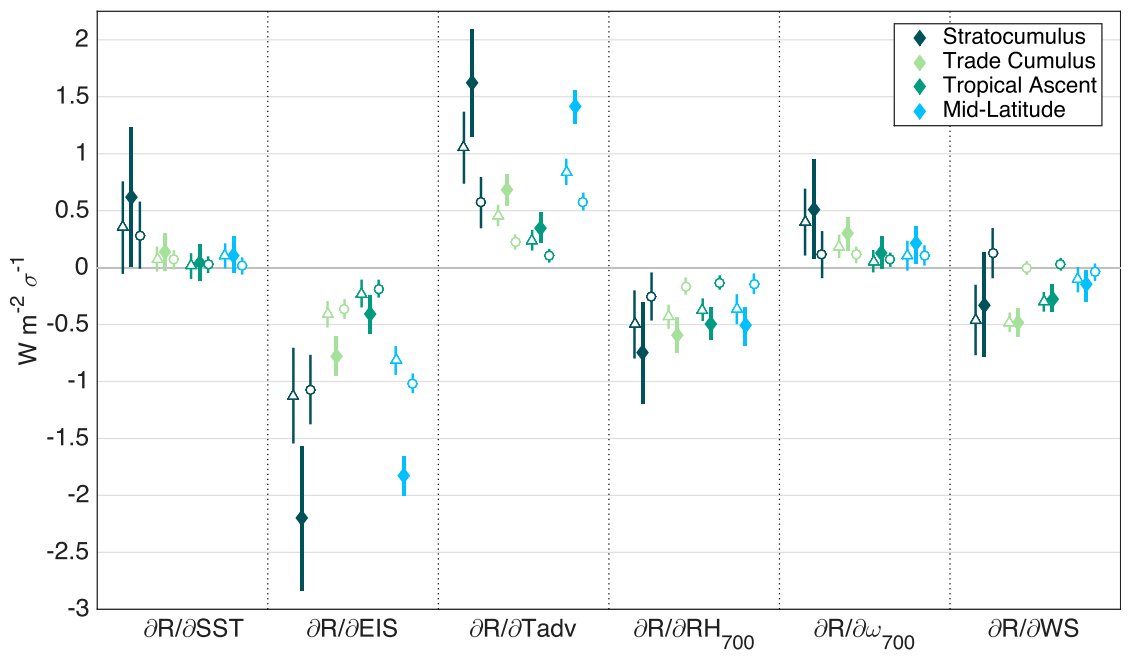

FIG. 8. Area-weighted mean low-cloud radiative response coefficients in each regime from CERES-FBCT. Total low-cloud radiative response coefficients $(\diamond)$ are flanked by the individual components depicting the effect of changes in nonobscured low-cloud fraction $(\Delta)$ and changes in low-cloud optical depth and cloud-top pressure $(\bigcirc)$. Vertical error bars depict $95 \%$ confidence intervals.

latent heating in updrafts. Subsequent entrainment of dry air from aloft may explain lower cloud optical thickness. Increases in cloud-top altitude associated with a deeper MBL may also be contributing to reductions in outgoing LW radiation. In contrast, at midlatitudes where cold SSTs tend to favor smaller surface moisture fluxes and the MBL is often stabilized by warm Tadv (Fig. 2c and Zheng and Li 2019), changes in wind speed have a weaker and more variable impact on low-cloud amount. This, combined with small increases in low-cloud optical depth and a deeper MBL, produces a weak and variable impact on the low-cloud radiative effect (Fig. 5f).

As shown in Figs. S14-S16, the above relationships hold across multiple satellite datasets based on independent retrieval methodologies, different observational platforms, and different time periods. For an independent check on the coefficients, we compared the results from CERESFBCT and MODIS for the period 2002-18 with results from ISCCP and PATMOS-x for the period 1984-99. Shifts in the selected time periods have minimal impact on the results. Within each regime, distributions of the regression slopes show generally good consistency across all datasets, indicating that our results are robust and not limited to a particular observational dataset.

\section{Summary and discussion}

We evaluated the spatially varying sensitivity of marine low-level clouds and their radiative effects to observed interannual variability in large-scale meteorological conditions over the global oceans. In particular, we assessed the low-cloud response to a comprehensive set of meteorological parameters that set the boundary conditions for the MBL. To derive physically meaningful relationships among low clouds and meteorology, particularly in regions of pervasive upper-level cloud cover, we developed two novel methods to account for upper-level cloud variability and obscuration effects. This enabled us to implement cloud-controlling factor analysis at a near-global scale for the first time and to improve upon previous studies that examined limited areas of the planet. The analysis illuminates physical mechanisms underlying the low-cloud response to meteorology in different climate regimes and provides new observational constraints on marine lowcloud feedbacks. Figure 9 presents an idealized meridional cross section summarizing what observations tell us about how low-level clouds respond to variations in each meteorological parameter.

EIS and Tadv emerge as the dominant low-level cloud-controlling factors across much of the global ocean. Their coefficients exhibit strong spatial coherence with the strongest response in the eastern ocean stratocumulus and midlatitude regimes. Stronger inversions are associated with enhanced stability and reduced vertical exchange at cloud top, which traps moisture in the MBL, favoring more and optically thicker low-level cloud. Changes in Tadv alter the stability of the air-sea interface, vertical fluxes of heat and moisture, and vertical mixing within the MBL. Cold Tadv introduces relatively cool and dry air over warmer water, which reduces lowlevel stability and triggers the release of moisture into the MBL, favoring more and optically thicker low-level 
a) Meteorological conditions that favor less low cloud

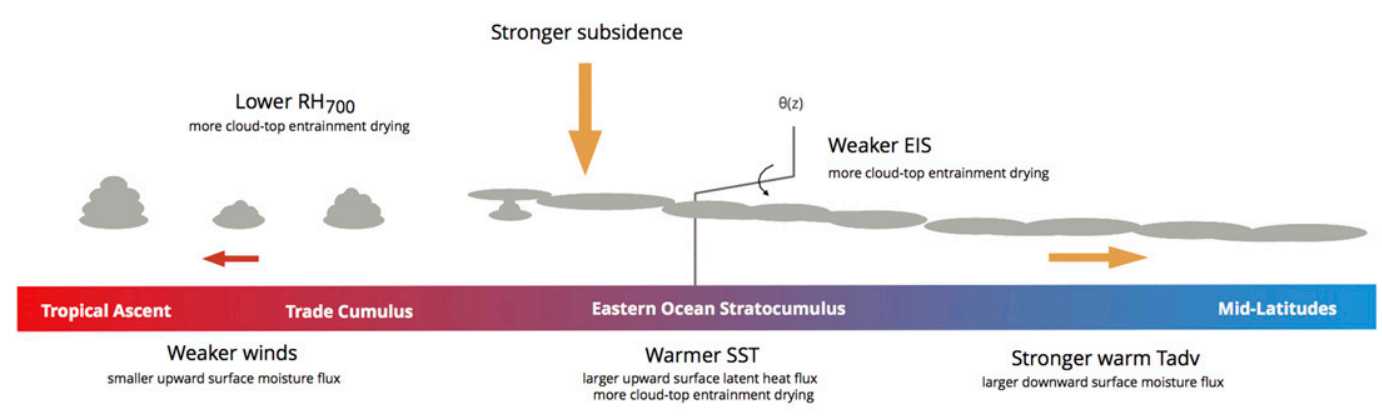

b) Meteorological conditions that favor more low cloud

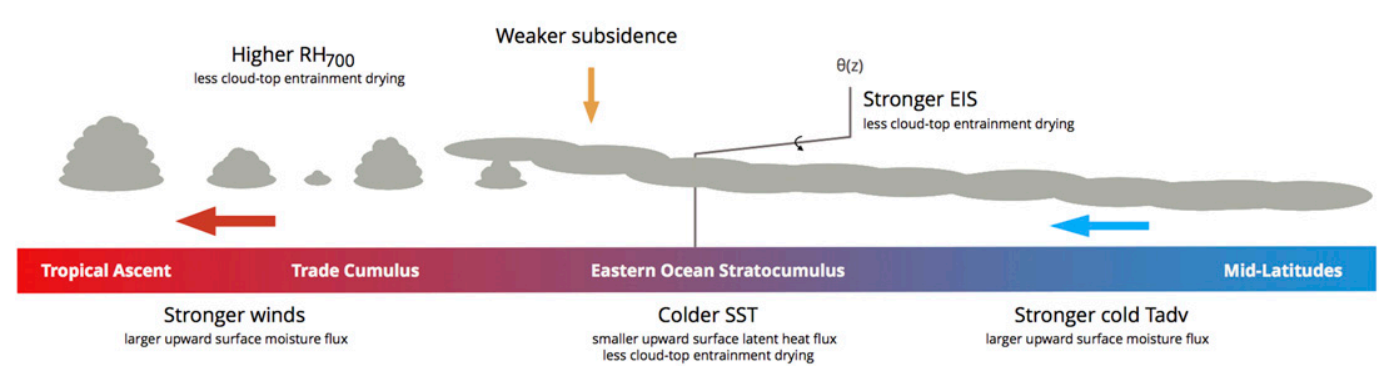

FIG. 9. Schematic summary of how low-level clouds respond to changes in each large-scale meteorological cloudcontrolling factor.

cloud. In contrast, perturbations in SST have a regionally varying impact on marine low-cloud fields. Warmer SST increases the temperature and saturation vapor pressure in the MBL, promoting more in-cloud latent heating. This increases the production of turbulence in the MBL and, in turn, increases entrainment of dry air at cloud top, which tends to desiccate the MBL. Warmer SST drives pronounced reductions in low-cloud cover and optical depth in the eastern ocean stratocumulus regime, where the free troposphere is dry and the MBL is usually shallow, well mixed, and coupled to the surface. Perturbations in SST have a relatively weak and variable impact in the trade cumulus regime, perhaps linked to the cumulus valve mechanism (Vial et al. 2017), as well as the midlatitude regime, where a humid free troposphere reduces entrainment drying. In both regimes, the MBL often decouples from the surface moisture supply (Bretherton and Wyant 1997; Zheng and Li 2019). By reducing the efficiency of entrainment drying, higher $\mathrm{RH}_{700}$ favors enhanced low-level cloudiness. It has the strongest influence in the tropics and a generally weaker impact at midlatitudes. Changes in $\omega_{700}$ influence the depth of the MBL, with stronger subsidence acting to reduce the MBL depth and low-level cloudiness (Myers and Norris 2013). Changes in surface wind speed affect surface moisture fluxes and the depth of the MBL (e.g., Mieslinger et al. 2019). Over low-latitude oceans, where cold Tadv destabilizes the air-sea interface, stronger winds increase evaporation from the surface, favoring increases in low-level cloud amount. In contrast, wind speed variations have less effect at midlatitudes, where warm advection frequently stabilizes the MBL, reducing upward vertical mixing of moisture (Zheng and Li 2019).

One limitation of our analysis, owing to the nature of passive satellite data, is the inability to determine the TOA radiative impact of low-cloud changes that occur under free-tropospheric clouds. Such radiative perturbations could be important where free-tropospheric clouds are transmissive and low clouds are ubiquitous. This could be evaluated in future studies using data collected by spaceborne active sensors. Another limitation of our study is that we do not consider low-level clouds over land. By accounting for factors such as surface roughness, vegetation, soil moisture, and aerosols, our present framework could be modified in future studies to understand factors governing low clouds over continents. Additionally, more cloud-controlling factors, such as aerosols or vertical wind shear (Nuijens and Siebesma 2019), could also be investigated in future studies of marine low clouds. 
The meteorological cloud radiative kernels presented in this study may be useful for a wide variety of applications. For example, they could be used to explore how various SST "pattern effects" (Stevens et al. 2016) and perturbations in the large-scale atmospheric circulation (Zelinka et al. 2018) influence low-cloud feedbacks to global warming. Alternatively, by multiplying the coefficients by meteorological anomalies $x_{i}$ regressed upon various climate indices, they could be used to evaluate low-cloud feedbacks to various modes of coupled atmosphere-ocean variability (Yuan et al. 2018). They might also serve as a useful tool for interpreting multidecadal cloud and climate trends in the observational record (Seethala et al. 2015; Norris et al. 2016). Last but not least, they provide a useful benchmark for evaluating and improving the performance of models spanning a wide range of scales (e.g., for remedying long-standing biases in low-cloud and radiation fields simulated by global climate models and narrowing uncertainty in simulated low-cloud feedback). Given their utility for these and other studies, the coefficients will be made publicly available.

Acknowledgments. R. C. S. and J. R. N were supported by NASA under Grant 80NSSC18K1020. The work of T. A. M., M. D. Z., and S. A. K. was supported by the DOE's Regional and Global Model Analysis Program and was performed under the auspices of the U.S. DOE by Lawrence Livermore National Laboratory under contract DE-AC52-07NA27344. CERES FBCT data are available at https://ceres.larc.nasa.gov/data/. ERA5 data were downloaded at https://cds.climate.copernicus.eu/cdsapp\#!/ home. MERRA-2 data were downloaded at https:// disc.gsfc.nasa.gov/. NOAA OI v2 SST data were downloaded from the NOAA/OAR/ESRL PSD, Boulder, Colorado, USA, at https://psl.noaa.gov/data/gridded/ data.noaa.oisst.v2.html. MODIS C6.1 data were downloaded at atmos.gsfc.nasa.gov/MOD06_L2/index.html. ISCCP data were downloaded at https://eosweb.larc.nasa.gov/ project/isccp/isccp_d1_table. PATMOS-x data were downloaded at http://climserv.ipsl.polytechnique.fr/gewexca/ instruments/PATMOSX.html. Readers interested in using the meteorological cloud radiative kernels presented in this study are encouraged to contact the corresponding author.

\section{APPENDIX}

\section{Regression Coefficient Uncertainty}

We quantify the uncertainty of the regression coefficients by formulating a $95 \%$ confidence interval at each grid box as

$$
\frac{\partial R}{\partial x_{i}} \pm t \sqrt{\mathbf{C}_{i i}} \sqrt{\frac{N_{\text {nom }}}{N_{\text {eff }}}}=\frac{\partial R}{\partial x_{i}} \pm \delta_{i},
$$

where $t$ is the critical value of the Student's $t$ distribution at the $(1-\alpha / 2) 100 \%$ significance level with degrees of freedom df $=N_{\text {eff }}-(n+1)$, where $n$ is the number of predictors, and $\alpha=0.05$. Also, $\mathbf{C}_{i i}$ represents the diagonal components of the variance-covariance matrix of meteorological anomalies $x_{i}^{\prime}$, given by $\mathbf{C}=\hat{\sigma}^{2}\left(\mathbf{X}^{\mathrm{T}} \mathbf{X}\right)^{-1}$, where $\mathbf{X}$ is the data matrix with columns composed of detrended interannual $x_{i}^{\prime}$ and $\hat{\sigma}^{2}$ is the mean squared error of the regression model. Finally, $N_{\text {nom }}$ is the nominal temporal number of grid boxes while $N_{\text {eff }}$ is the effective temporal number of grid boxes. We estimate their ratio as $\left(1+r_{t}\right) /$ $\left(1-r_{t}\right)$, where $r_{t}$ is the lag- 1 temporal autocorrelation of cloud-radiative anomalies.

Uncertainty ranges for spatially averaged regression coefficients are calculated as

$$
\left\langle\frac{\partial R}{\partial x_{i}}\right\rangle \pm \sqrt{\frac{\sum_{j=1}^{N_{\text {nom }}^{*}} w_{j}^{2} \delta_{j}^{2}}{\sum_{j=1}^{N_{\text {nom }}^{*}} w_{j}^{2}}} \sqrt{\frac{N_{\text {nom }}^{*}}{N_{\text {eff }}^{*}}},
$$

where $w_{j}$ represents the cosine of latitude, $\delta_{j}$ is given by Eq. (A1), $N_{\text {nom }}^{*}$ is the nominal spatial number of $5^{\circ} \times 5^{\circ}$ grid boxes, and $N_{\text {eff }}^{*}$ is the effective spatial number of grid boxes; $N_{\text {eff }}^{*}$ is calculated using Eq. (5) of Bretherton et al. (1999).

\section{REFERENCES}

Adebiyi, A. A., and P. Zuidema, 2018: Low cloud cover sensitivity to biomass-burning aerosols and meteorology over the southeast Atlantic. J. Climate, 31, 4329-4346, https://doi.org/10.1175/ JCLI-D-17-0406.1.

Bellomo, K., A. C. Clement, L. N. Murphy, L. M. Polvani, and M. A. Cane, 2016: New observational evidence for a positive cloud feedback that amplifies the Atlantic Multidecadal Oscillation. Geophys. Res. Lett., 43, 9852-9859, https://doi.org/ 10.1002/2016GL069961.

Bretherton, C. S., 2015: Insights into low-latitude cloud feedbacks from high-resolution models. Philos. Trans. Roy. Soc., A373, 20140415, https://doi.org/10.1098/RSTA.2014.0415.

_- and M. C. Wyant, 1997: Moisture transport, lowertropospheric stability, and decoupling of cloud-topped boundary layers. J. Atmos. Sci., 54, 148-167, https://doi.org/ 10.1175/1520-0469(1997)054<0148:MTLTSA > 2.0.CO;2.

greenhouse-warmed climate: Results from Lagrangian LES of a subtropical marine cloudiness transition. J. Adv. Model. Earth Syst., 6, 91-114, https://doi.org/10.1002/2013MS000250.

, M. Widmann, V. P. Dymnikov, J. M. Wallace, and I. Bladé, 1999: The effective number of spatial degrees of freedom of a 
time-varying field. J. Climate, 12, 1990-2009, https://doi.org/ 10.1175/1520-0442(1999)012<1990:TENOSD > 2.0.CO;2.

$\longrightarrow$, P. N. Blossey, and C. R. Jones, 2013: Mechanisms of marine low cloud sensitivity to idealized climate perturbations: A single-LES exploration extending the CGILS cases. J. Adv. Model. Earth Syst., 5, 316-337, https://doi.org/10.1002/jame.20019.

Brient, F., and T. Schneider, 2016: Constraints on climate sensitivity from space-based measurements of low-cloud reflection. J. Climate, 29, 5821-5835, https://doi.org/10.1175/ JCLI-D-15-0897.1.

Brown, P. T., M. S. Lozier, R. Zhang, and W. Li, 2016: The necessity of cloud feedback for a basin-scale Atlantic Multidecadal Oscillation. Geophys. Res. Lett., 43, 3955-3963, https://doi.org/10.1002/2016GL068303.

Brueck, M., L. Nuijens, and B. Stevens, 2015: On the seasonal and synoptic time-scale variability of the North Atlantic trade wind region and its low-level clouds. J. Atmos. Sci., 72, 1428-1446, https://doi.org/10.1175/JAS-D-14-0054.1.

Cesana, G., A. D. Del Genio, A. S. Ackerman, M. Kelley, G. Elsaesser, A. M. Fridlind, Y. Cheng, and M.-S. Yao, 2019: Evaluating models' response of tropical low clouds to SST forcings using CALIPSO observations. Atmos. Chem. Phys., 19, 2813-2832, https://doi.org/10.5194/acp-19-2813-2019.

Christensen, M. W., G. G. Carrió, G. L. Stephens, and W. R. Cotton, 2013: Radiative impacts of free-tropospheric clouds on the properties of marine stratocumulus. J. Atmos. Sci., 70, 3102-3118, https://doi.org/10.1175/JAS-D-12-0287.1.

Dee, D. P., and Coauthors, 2011: The ERA-Interim reanalysis: Configuration and performance of the data assimilation system. Quart. J. Roy. Meteor. Soc., 137, 553-597, https://doi.org/ 10.1002/qj.828.

Eastman, R., and R. Wood, 2018: The competing effects of stability and humidity on subtropical stratocumulus entrainment and cloud evolution from a Lagrangian perspective. J. Atmos. Sci., 75, 2563-2578, https://doi.org/10.1175/JAS-D-18-0030.1.

Eitzen, Z. A., W. Su, K.-M. Xu, N. Loeb, M. Sun, D. Doelling, F. Rose, and A. Bodas-Salcedo, 2017: Evaluation of a general circulation model by the CERES flux-by-cloud type simulator. J. Geophys. Res. Atmos., 122, 10 655-10 668, https://doi.org/ 10.1002/2017JD027076.

Gelaro, R., and Coauthors, 2017: The Modern-Era Retrospective Analysis for Research and Applications, version 2 (MERRA-2). J. Climate, 30, 5419-5454, https://doi.org/10.1175/JCLI-D-16-0758.1.

Georgakakos, K. P., and R. L. Bras, 1984: A hydrologically useful station precipitation model: 1. Formulation. Water Resour. Res., 20, 1585-1596, https://doi.org/10.1029/WR020i011p01585.

Grise, K. M., and B. Medeiros, 2016: Understanding the varied influence of midlatitude jet position on clouds and cloud radiative effects in observations and global climate models. J. Climate, 29, 9005-9025, https://doi.org/10.1175/JCLI-D-16-0295.1.

Heidinger, A. K., M. J. Foster, A. Walther, and X. Zhao, 2014: The Pathfinder Atmospheres-Extended AVHRR climate dataset. Bull. Amer. Meteor. Soc., 95, 909-922, https://doi.org/10.1175/ BAMS-D-12-00246.1.

Kawai, H., T. Koshiro, and M. J. Webb, 2017: Interpretation of factors controlling low cloud cover and low cloud feedback using a unified predictive index. J. Climate, 30, 9119-9131, https://doi.org/10.1175/JCLI-D-16-0825.1.

Kazil, J., G. Feingold, and T. Yamaguchi, 2016: Wind speed response of marine non-precipitating stratocumulus clouds over a diurnal cycle in cloud-system resolving simulations. Atmos. Chem. Phys., 16, 5811-5839, https://doi.org/10.5194/ acp-16-5811-2016.
Kelleher, M. K., and K. M. Grise, 2019: Examining Southern Ocean cloud controlling factors on daily time scales and their connections to midlatitude weather systems. J. Climate, 32, 5145-5160, https://doi.org/10.1175/JCLI-D-18-0840.1.

Klein, S. A., and D. L. Hartmann, 1993: The seasonal cycle of low stratiform clouds. J. Climate, 6, 1587-1606, https://doi.org/ 10.1175/1520-0442(1993)006<1587:TSCOLS $>2.0$.CO;2.

,-- , and J. R. Norris, 1995: On the relationships among lowcloud structure, sea surface temperature, and atmospheric circulation in the summertime northeast Pacific. J. Climate, $\mathbf{8}$, 1140-1155, https://doi.org/10.1175/1520-0442(1995)008<1140: OTRALC $>2.0 . \mathrm{CO} ; 2$.

—, A. Hall, J. R. Norris, and R. Pincus, 2017: Low-cloud feedbacks from cloud-controlling factors: A review. Shallow Clouds, Water Vapor, Circulation, and Climate Sensitivity, R. Pincus et al., Eds., Springer, 135-157.

Li, J., J. Huang, K. Stamnes, T. Wang, Q. Lv, and H. Jin, 2015: A global survey of cloud overlap based on CALIPSO and CloudSat measurements. Atmos. Chem. Phys., 15, 519-536, https://doi.org/10.5194/acp-15-519-2015.

Liu, J.-W., S.-P. Xie, S. Yang, and S.-P. Zhang, 2016: Low-cloud transitions across the Kuroshio front in the East China Sea. J. Climate, 29, 4429-4443, https://doi.org/10.1175/JCLI-D-15-0589.1.

Mauger, G. S., and J. R. Norris, 2010: Assessing the impact of meteorological history on subtropical cloud fraction. J. Climate, $\mathbf{2 3}$, 2926-2940, https://doi.org/10.1175/2010JCLI3272.1.

McCoy, D. T., R. Eastman, D. L. Hartmann, and R. Wood, 2017: The change in low cloud cover in a warmed climate inferred from AIRS, MODIS, and ERA-Interim. J. Climate, 30, 3609-3620, https://doi.org/10.1175/JCLI-D-15-0734.1.

Medeiros, B., and B. Stevens, 2011: Revealing differences in GCM representations of low clouds. Climate Dyn., 36, 385-399, https://doi.org/10.1007/s00382-009-0694-5.

Middlemas, E. A., A. C. Clement, B. Medeiros, and B. Kirtman, 2019: Cloud radiative feedbacks and El Niño-Southern Oscillation. J. Climate, 32, 4661-4680, https://doi.org/10.1175/ JCLI-D-18-0842.1.

Mieslinger, T., Á. Horváth, S. A. Buehler, and M. Sakradzija, 2019: The dependence of shallow cumulus macrophysical properties on large-scale meteorology as observed in ASTER imagery. J. Geophys. Res. Atmos., 124, 11477-11 505, https://doi.org/ 10.1029/2019JD030768.

Minnis, P., and Coauthors, 2011: CERES Edition-2 cloud property retrievals using TRMM VIRS and Terra and Aqua MODIS data: Part I: Algorithms. IEEE Trans. Geosci. Remote Sens., 49, 4374-4400, https://doi.org/10.1109/TGRS.2011.2144601.

Miyamoto, A., H. Nakamura, and T. Miyasaka, 2018: Influence of the subtropical high and storm track on low-cloud fraction and its seasonality over the south Indian Ocean. J. Climate, 31, 4017-4039, https://doi.org/10.1175/JCLI-D-17-0229.1.

Myers, T. A., and J. R. Norris, 2013: Observational evidence that enhanced subsidence reduces subtropical marine boundary layer cloudiness. J. Climate, 26, 7507-7524, https://doi.org/ 10.1175/JCLI-D-12-00736.1.

, and - 2015: On the relationships between subtropical clouds and meteorology in observations and CMIP3 and CMIP5 models. J. Climate, 28, 2945-2967, https://doi.org/ 10.1175/JCLI-D-14-00475.1.

, and - 2016: Reducing the uncertainty in subtropical cloud feedback. Geophys. Res. Lett., 43, 2144-2148, https://doi.org/ 10.1002/2015GL067416.

, C. R. Mechoso, G. V. Cesana, M. J. DeFlorio, and D. E. Waliser, 2018a: Cloud feedback key to marine heatwave off 
Baja California. Geophys. Res. Lett., 45, 4345-4352, https:// doi.org/10.1029/2018GL078242.

— - _ , and M. J. DeFlorio, 2018b: Coupling between marine boundary layer clouds and summer-to-summer sea surface temperature variability over the North Atlantic and Pacific. Climate Dyn., 50, 955-969, https://doi.org/10.1007/s00382-017-3651-8.

Naud, C. M., J. F. Booth, and A. D. Del Genio, 2016: The relationship between boundary layer stability and cloud cover in the post-cold-frontal region. J. Climate, 29, 8129-8149, https:// doi.org/10.1175/JCLI-D-15-0700.1.

Neggers, R., B. Stevens, and J. D. Neelin, 2006: A simple equilibrium model for shallow-cumulus-topped mixed layers. Theor. Comput. Fluid Dyn., 20, 305-322, https://doi.org/10.1007/ s00162-006-0030-1.

Norris, J. R., 1998: Low cloud type over the ocean from surface observations. Part II: Geographical and seasonal variations. J. Climate, 11, 383-403, https://doi.org/10.1175/1520-0442(1998) $011<0383$ :LCTOTO $>2.0$. CO;2.

_- , and C. B. Leovy, 1994: Interannual variability in stratiform cloudiness and sea surface temperature. J. Climate, $\mathbf{7}$, 1915-1925, https://doi.org/10.1175/1520-0442(1994)007<1915: IVISCA $>2.0 . \mathrm{CO} ; 2$.

_ , and S. F. Iacobellis, 2005: North Pacific cloud feedbacks inferred from synoptic-scale dynamic and thermodynamic relationships. J. Climate, 18, 4862-4878, https://doi.org/10.1175/ JCLI3558.1.

— , R. J. Allen, A. T. Evan, M. D. Zelinka, C. W. O'Dell, and S. A. Klein, 2016: Evidence for climate change in the satellite cloud record. Nature, 536, 72-75, https://doi.org/10.1038/ nature 18273 .

Nuijens, L., and A. P. Siebesma, 2019: Boundary layer clouds and convection over subtropical oceans in our current and in a warmer climate. Curr. Climate Change Rep., 5, 80-94, https:// doi.org/10.1007/S40641-019-00126-X.

- I. Serikov, L. Hirsch, K. Lonitz, and B. Stevens, 2014: The distribution and variability of low-level cloud in the North Atlantic trades. Quart. J. Roy. Meteor. Soc., 140, 2364-2374, https://doi.org/10.1002/qj.2307.

Platnick, S., and Coauthors, 2015: MODIS cloud optical properties: User guide for the Collection 6 Level-2 MOD06/MYD06 product and associated Level-3 datasets, version 1. NASA Goddard Space Flight Center, 141 pp., https://modis-images. gsfc.nasa.gov/_docs/C6MOD06OPUserGuide.pdf.

Qu, X., A. Hall, S. A. Klein, and P. M. Caldwell, 2014: On the spread of changes in marine low cloud cover in climate model simulations of the 21st century. Climate Dyn., 42, 2603-2626, https://doi.org/10.1007/s00382-013-1945-z.

,,--- , and A. M. DeAngelis, 2015: Positive tropical marine low-cloud cover feedback inferred from cloud-controlling factors. Geophys. Res. Lett., 42, 7767-7775, https://doi.org/ 10.1002/2015GL065627.

Reynolds, R. W., N. A. Rayner, T. M. Smith, D. C. Stokes, and W. Wang, 2002: An improved in situ and satellite SST analysis for climate. J. Climate, 15, 1609-1625, https://doi.org/10.1175/ 1520-0442(2002)015<1609:AIISAS > 2.0.CO;2.

Rieck, M., L. Nuijens, and B. Stevens, 2012: Marine boundary layer cloud feedbacks in a constant relative humidity atmosphere. J. Atmos. Sci., 69, 2538-2550, https://doi.org/ 10.1175/JAS-D-11-0203.1.

Rossow, W. B., and R. A. Schiffer, 1999: Advances in understanding clouds from ISCCP. Bull. Amer. Meteor. Soc., 80, 2261-2288, https://doi.org/10.1175/1520-0477(1999)080<2261: AIUCFI $>2.0 . \mathrm{CO} ; 2$.
Schneider, S. H., 1972: Cloudiness as a global climatic feedback mechanism: The effects on the radiation balance and surface temperature of variations in cloudiness. J. Atmos. Sci., 29, 1413-1422, https://doi.org/10.1175/1520-0469(1972)029<1413: CAAGCF $>2.0 . \mathrm{CO} ; 2$.

Schneider, T., C. M. Kaul, and K. G. Pressel, 2019: Possible climate transitions from breakup of stratocumulus decks under greenhouse warming. Nat. Geosci., 12, 163-167, https://doi.org/ 10.1038/s41561-019-0310-1.

Seethala, C., J. R. Norris, and T. A. Myers, 2015: How has subtropical stratocumulus and associated meteorology changed since the 1980s? J. Climate, 28, 8396-8410, https://doi.org/ 10.1175/JCLI-D-15-0120.1.

Sherwood, S. C., S. Bony, and J.-L. Dufresne, 2014: Spread in model climate sensitivity traced to atmospheric convective mixing. Nature, 505, 37-42, https://doi.org/10.1038/nature12829.

Slingo, A., 1990: Sensitivity of the Earth's radiation budget to changes in low clouds. Nature, 343, 49-51, https://doi.org/ 10.1038/343049a0.

Stevens, B., S. C. Sherwood, S. Bony, and M. J. Webb, 2016: Prospects for narrowing bounds on Earth's equilibrium climate sensitivity. Earth's Future, 4, 512-522, https://doi.org/ 10.1002/2016EF000376.

Tan, Z., T. Schneider, J. Teixeira, and K. G. Pressel, 2017: Largeeddy simulation of subtropical cloud-topped boundary layers: 2. Cloud response to climate change. J. Adv. Model. Earth Syst., 9, 19-38, https://doi.org/10.1002/2016MS000804.

Thorsen, T. J., S. Kato, N. G. Loeb, and F. G. Rose, 2018: Observation-based decomposition of radiative perturbations and radiative kernels. J. Climate, 31, 10 039-10 058, https:// doi.org/10.1175/JCLI-D-18-0045.1.

van der Dussen, J. J., S. R. De Roode, S. Dal Gesso, and A. P. Siebesma, 2015: An LES model study of the influence of the free tropospheric thermodynamic conditions on the stratocumulus response to a climate perturbation. J. Adv. Model. Earth Syst., 7, 670-691, https://doi.org/10.1002/2014MS000380.

Vial, J., S. Bony, J.-L. Dufresne, and R. Roehrig, 2016: Coupling between lower-tropospheric convective mixing and low-level clouds: Physical mechanisms and dependence on convection scheme. J. Adv. Model. Earth Syst., 8, 1892-1911, https:// doi.org/10.1002/2016MS000740.

, _ _ B. Stevens, and R. Vogel, 2017: Mechanisms and model diversity of trade-wind shallow cumulus cloud feedbacks: A review. Shallow Clouds, Water Vapor, Circulation, and Climate Sensitivity, R. Pincus et al., Eds., Springer, 159-181.

Wood, R., 2012: Stratocumulus clouds. Mon. Wea. Rev., 140, 2373-2423, https://doi.org/10.1175/MWR-D-11-00121.1.

, and C. S. Bretherton, 2004: Boundary layer depth, entrainment, and decoupling in the cloud-capped subtropical and tropical marine boundary layer. J. Climate, 17, 3576-3588, https://doi.org/ 10.1175/1520-0442(2004)017<3576:BLDEAD > 2.0.CO;2. , and —-, 2006: On the relationship between stratiform low cloud cover and lower-tropospheric stability. J. Climate, 19, 6425-6432, https://doi.org/10.1175/JCLI3988.1.

Wyant, M. C., C. S. Bretherton, H. A. Rand, and D. E. Stevens, 1997: Numerical simulations and a conceptual model of the stratocumulus to trade cumulus transition. J. Atmos. Sci., 54, 168-192, https://doi.org/10.1175/1520-0469(1997)054<0168: NSAACM $>2.0 . \mathrm{CO} ; 2$.

Xiao, H., C.-M. Wu, and C. R. Mechoso, 2011: Buoyancy reversal, decoupling and the transition from stratocumulus to shallow cumulus topped marine boundary layers. Climate Dyn., 37, 971-984, https://doi.org/10.1007/s00382-010-0882-3. 
Yuan, T., and L. Oreopoulos, 2013: On the global character of overlap between low and high clouds. Geophys. Res. Lett., 40, 5320-5326, https://doi.org/10.1002/grl.50871.

, —_, M. Zelinka, H. Yu, J. R. Norris, M. Chin, S. Platnick, and K. Meyer, 2016: Positive low cloud and dust feedbacks amplify tropical North Atlantic Multidecadal Oscillation. Geophys. Res. Lett., 43, 1349-1356, https://doi.org/10.1002/2016GL067679.

, - _ , S. E. Platnick, and K. Meyer, 2018: Observations of local positive low cloud feedback patterns and their role in internal variability and climate sensitivity. Geophys. Res. Lett., 45, 4438-4445. https://doi.org/10.1029/2018GL077904.

Zelinka, M. D., S. A. Klein, and D. L. Hartmann, 2012a: Computing and partitioning cloud feedbacks using cloud property histograms. Part I: Cloud radiative kernels. J. Climate, 25, 3715-3735, https://doi.org/10.1175/JCLI-D-11-00248.1.

,$- \ldots$, and $\longrightarrow, 2012 \mathrm{~b}$ : Computing and partitioning cloud feedbacks using cloud property histograms. Part II: Attribution to changes in cloud amount, altitude, and optical depth. J. Climate, 25, 3736-3754, https://doi.org/10.1175/JCLI-D-11-00249.1.

, C. Zhou, and S. A. Klein, 2016: Insights from a refined decomposition of cloud feedbacks. Geophys. Res. Lett., 43, 9259-9269, https://doi.org/10.1002/2016GL069917.

, K. M. Grise, S. A. Klein, C. Zhou, A. M. DeAngelis, and M. W. Christensen, 2018: Drivers of the low-cloud response to poleward jet shifts in the North Pacific in observations and models. J. Climate, 31, 7925-7947, https://doi.org/10.1175/ JCLI-D-18-0114.1.

— T. A. Myers, D. T. McCoy, S. Po-Chedley, P. M. Caldwell, P. Ceppi, S. A. Klein, and K. E. Taylor, 2020: Causes of higher climate sensitivity in CMIP6 models. Geophys. Res. Lett., 47, e2019GL085782, https://doi.org/10.1029/2019GL085782.

Zhai, C., J. H. Jiang, and H. Su, 2015: Long-term cloud change imprinted in seasonal cloud variation: More evidence of high climate sensitivity. Geophys. Res. Lett., 42, 8729-8737, https:// doi.org/10.1002/2015GL065911.

Zhang, H., A. Clement, and P. Di Nezio, 2014: The South Pacific meridional mode: A mechanism for ENSO-like variability. J. Climate, 27, 769-783, https://doi.org/10.1175/ JCLI-D-13-00082.1.

Zheng, Y., and Z. Li, 2019: Episodes of warm-air advection causing cloud-surface decoupling during the MARCUS. J. Geophys. Res. Atmos., 124, 12 227-12 243, https://doi.org/ 10.1029/2019JD030835.

Zhou, C., M. D. Zelinka, A. E. Dessler, and P. Yang, 2013: An analysis of the short-term cloud feedback using MODIS data. J. Climate, 26, 4803-4815, https://doi.org/10.1175/JCLI-D-12-00547.1.

Zhu, J., C. J. Poulsen, and J. E. Tierney, 2019: Simulation of Eocene extreme warmth and high climate sensitivity through cloud feedbacks. Sci. Adv., 5, eaax1874, https://doi.org/10.1126/ sciadv.aax1874. 